\title{
Effects of lesions of the nucleus accumbens core on choice between small certain rewards and large uncertain rewards in rats Rudolf N Cardinal* and Nathan J Howes
}

\author{
Address: Department of Experimental Psychology, University of Cambridge, Downing Street, Cambridge CB2 3EB, UK \\ Email: Rudolf N Cardinal* - Rudolf.Cardinal@pobox.com; Nathan J Howes - N.J.Howes.01@ @antab.net \\ * Corresponding author
}

Published: 28 May 2005

BMC Neuroscience 2005, 6:37 doi:10.1 I86/147|-2202-6-37

This article is available from: http://www.biomedcentral.com/I47/-2202/6/37

(C) 2005 Cardinal and Howes; licensee BioMed Central Ltd.

This is an Open Access article distributed under the terms of the Creative Commons Attribution License (http://creativecommons.org/licenses/by/2.0), which permits unrestricted use, distribution, and reproduction in any medium, provided the original work is properly cited.
Received: 18 April 2005

Accepted: 28 May 2005

\begin{abstract}
Background: Animals must frequently make choices between alternative courses of action, seeking to maximize the benefit obtained. They must therefore evaluate the magnitude and the likelihood of the available outcomes. Little is known of the neural basis of this process, or what might predispose individuals to be overly conservative or to take risks excessively (avoiding or preferring uncertainty, respectively). The nucleus accumbens core (AcbC) is known to contribute to rats' ability to choose large, delayed rewards over small, immediate rewards; AcbC lesions cause impulsive choice and an impairment in learning with delayed reinforcement. However, it is not known how the AcbC contributes to choice involving probabilistic reinforcement, such as between a large, uncertain reward and a small, certain reward. We examined the effects of excitotoxic lesions of the $\mathrm{AcbC}$ on probabilistic choice in rats.
\end{abstract}

Results: Rats chose between a single food pellet delivered with certainty $(p=I)$ and four food pellets delivered with varying degrees of uncertainty $(p=1,0.5,0.25,0.125$, and 0.0625$)$ in a discrete-trial task, with the large-reinforcer probability decreasing or increasing across the session. Subjects were trained on this task and then received excitotoxic or sham lesions of the AcbC before being retested. After a transient period during which AcbC-lesioned rats exhibited relative indifference between the two alternatives compared to controls, AcbC-lesioned rats came to exhibit risk-averse choice, choosing the large reinforcer less often than controls when it was uncertain, to the extent that they obtained less food as a result. Rats behaved as if indifferent between a single certain pellet and four pellets at $p=0.32$ (sham-operated) or at $p=0.70$ (AcbClesioned) by the end of testing. When the probabilities did not vary across the session, AcbClesioned rats and controls strongly preferred the large reinforcer when it was certain, and strongly preferred the small reinforcer when the large reinforcer was very unlikely $(p=0.0625)$, with no differences between AcbC-lesioned and sham-operated groups.

Conclusion: These results support the view that the AcbC contributes to action selection by promoting the choice of uncertain, as well as delayed, reinforcement.

\section{Background}

Animals often need to choose between different courses of action on the basis of the eventual rewarding or reinforc- ing outcomes of those actions. However, the relationship between an action and an outcome is frequently uncertain: animals do not always obtain that for which they 
work. Therefore, animals must incorporate information on the probability of obtaining different rewards when making decisions about what to do. Little is known of the neural basis of this process. Furthermore, when making decisions under conditions of uncertainty, individuals vary as to how much uncertainty or risk they are willing to tolerate. Formally, individuals differ in how much they 'discount' the value of reinforcers as the uncertainty of the reinforcer increases (i.e. as the probability of the reinforcer declines, or the odds against obtaining the reinforcer increase) [1]. Risk taking is one aspect of the personality trait of impulsivity [2-4] and is a feature of a number of psychiatric disorders, including pathological gambling and certain personality disorders [5-8]. The term 'risk' implies exposure to the possibility of an aversive consequence [9], which may include the possibility of not obtaining an anticipated reward. In the appetitive domain, risk taking is exemplified by the tendency to choose large rewards that are very uncertain, in preference to smaller, certain rewards. Abnormal risk taking may reflect dysfunction of reinforcement learning systems that mediate the effects of uncertain reward or punishment.

The nucleus accumbens (Acb) is one candidate structure that may influence choice involving uncertainty. The Acb responds to anticipated rewards in humans, other primates, and rats [10-17], and is innervated by dopamine (DA) neurons that respond to errors in reward prediction in a manner appropriate for a teaching signal [18-21]. There is clear evidence that the Acb is involved in the processing of delayed reinforcement and its influence upon choice. Damage to the nucleus accumbens core (AcbC) produces impulsive choice in rats $[22,23]$, reducing their ability to choose large, delayed rewards in preference to small, immediate rewards, yet these and other similar lesions do not appear to impair rats' ability to discriminate reward size [23-31]. Furthermore, AcbC lesions impair rats' ability to learn instrumental actions when the outcomes of those actions are delayed [24]. The Acb may also be involved in the processing of uncertain or probabilistic reinforcement. DA neurons that innervate the Acb may fire in a manner related to reward probability [32-34] and the midbrain, the site of the cell bodies of these neurons, responds to stimulus uncertainty in humans [35]. A greater blood flow response is observed in the human Acb during the selection of high-reward/high-risk options, compared to low-reward/low-risk outcomes, in a task where the risk is of not winning [36], with similar activation to high-reward/high-risk option selection in a task where the risk is of losing [37]; this latter activation was correlated with personality measures of harm avoidance. However, these studies are correlative, and it is not known whether the AcbC is causally involved in regulating choice involving uncertain reinforcement.
In the present study, we sought to examine the contribution of the AcbC to choice involving probabilistic reinforcement in rats. We trained rats on a task in which they could choose regularly between a certain, small reward and an uncertain, large reward in discrete trials (Figure 1) and made excitotoxic AcbC lesions before retesting the rats postoperatively. Preoperatively, the proportion of choice trials in which the large reinforcer was chosen was approximately a linear function of the large-reinforcer probability. Postoperatively, after a transient period in which AcbC-lesioned rats were relatively indifferent between the two reinforcers, compared to sham-operated controls, a stable state emerged in which AcbC-lesioned rats chose the large, uncertain reinforcer less often than shams did. This pattern persisted regardless of whether the large-reinforcer probability increased or decreased across the session. AcbC-lesioned rats and controls continued to exhibit a strong preference for the large reinforcer when it was consistently certain, and a strong preference for the small, certain reinforcer when the large reinforcer was very unlikely; the lesioned and sham-operated groups did not differ from each other in either of these conditions. These results suggest that the AcbC is necessary for the normal impact of unlikely (as well as delayed) reinforcers upon choice.

\section{Results \\ Histology}

There were four postoperative deaths. Histological analysis revealed that the lesions were incomplete or encroached significantly on neighbouring structures in two subjects. These subjects were excluded; final group numbers were therefore 6 (AcbC) and 12 (sham). Lesions of the AcbC encompassed most of the core subregion; neuronal loss and associated gliosis extended in an anteroposterior direction from approximately $2.7 \mathrm{~mm}$ to 0.2 $\mathrm{mm}$ anterior to bregma, and did not extend ventrally or caudally into the ventral pallidum or olfactory tubercle. Damage to the ventromedial caudate-putamen was occasionally seen; damage to the nucleus accumbens shell (AcbSh) was restricted to the lateral edge of the dorsal shell. Schematics of the lesions are shown in Figure 2. Photomicrographs of lesions with identical parameters have been presented before $[24,38,39]$.

\section{Preoperative choice}

The groups remained matched for preoperative choice behaviour following later histological selection (Figure $3 a)$. Choice ratios (percentage choice of the large reinforcer, for each trial block) calculated across sessions 1012 (see Table 1) were analysed using the model lesion intent $_{2} \times($ large-reinforcer probability $5 \times S$ ). There was a robust effect of probability $\left(F_{3.3,52.9}=70.6, \tilde{\varepsilon}=.826, p<\right.$ .001 ) but no effect of lesion intent and no lesion intent $x$ probability interaction $(F s<1, N S)$. 


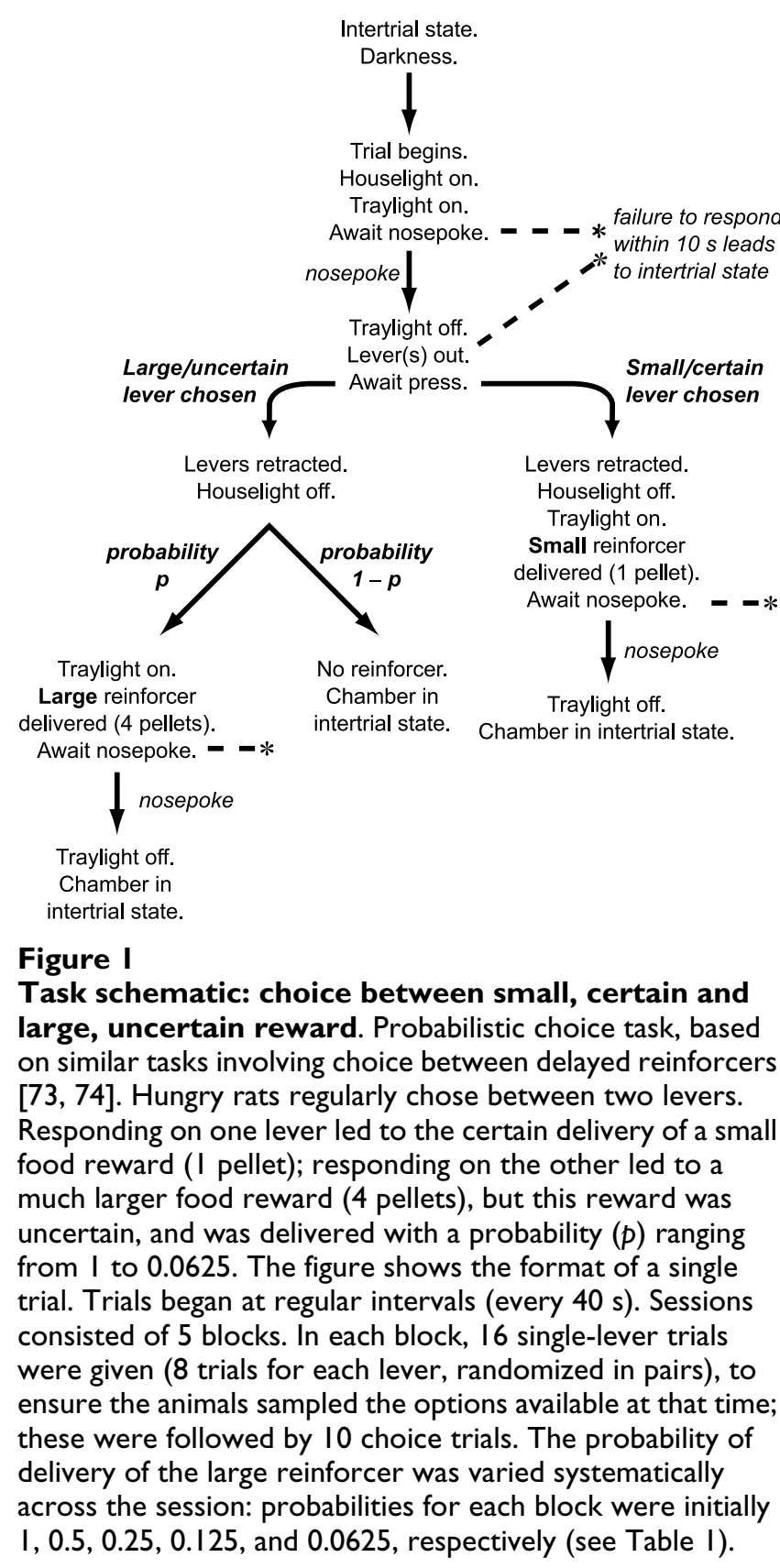

\section{Early postoperative choice}

In the initial postoperative period, AcbC-lesioned rats exhibited relative indifference between the two alternatives, choosing the large reinforcer close to $50 \%$ of the time at all large-reinforcer probabilities; as a result, AcbClesioned rats were more likely than shams to choose the large reinforcer when it was most uncertain (Figure $3 b$ ). An analysis of choice ratios calculated across sessions 1315 was performed using the ANOVA model lesion ${ }_{2} \times$ $\left(\right.$ probability $\left._{5} \times \mathrm{S}\right)$. This revealed a lesion $\times$ probability

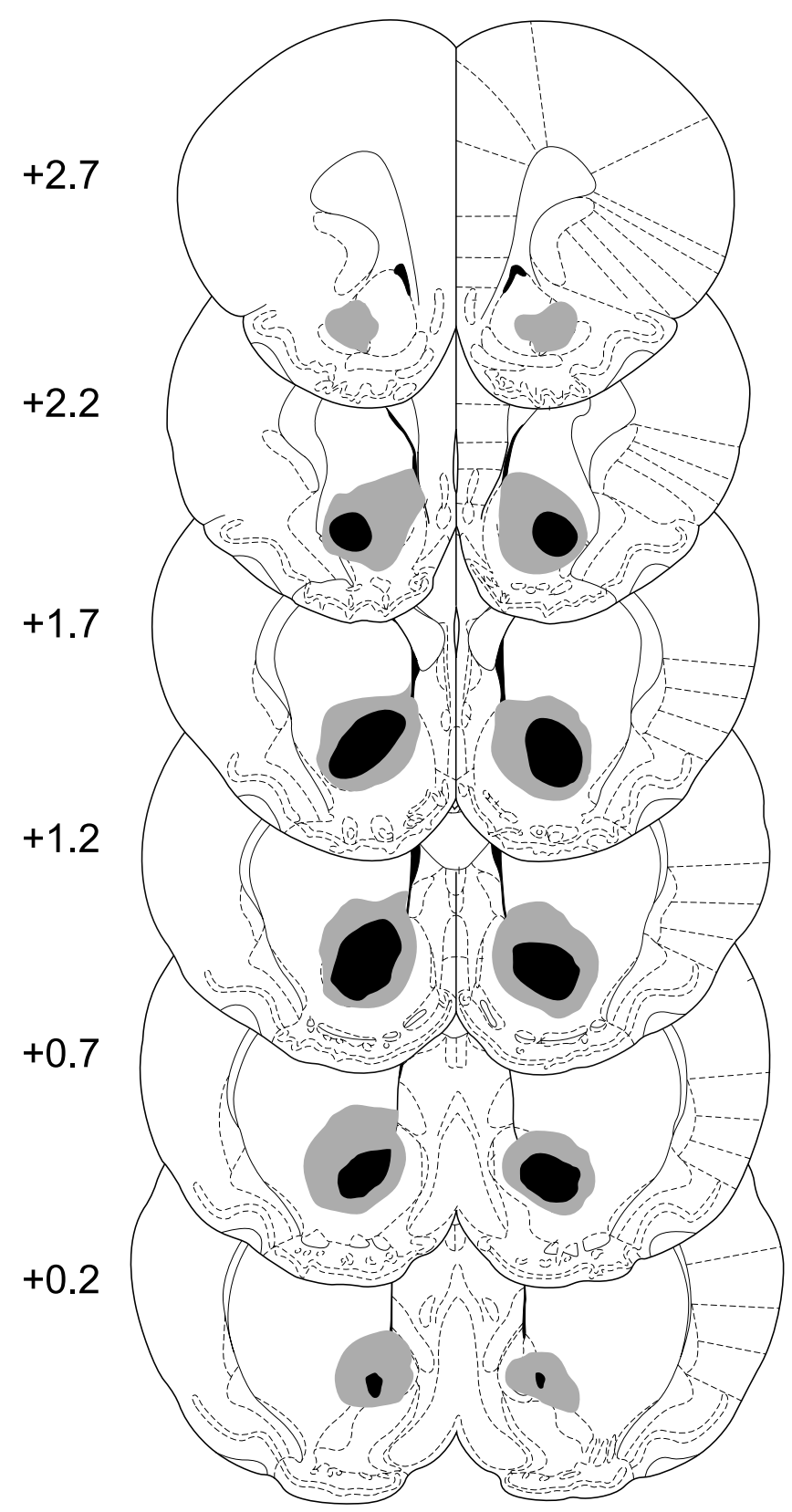

Figure 2

Schematic of lesions of the nucleus accumbens core. Black shading indicates the extent of neuronal loss common to all subjects; grey indicates the area lesioned in at least one subject. Coronal sections are (from top to bottom) +2.7 , $+2.2,+1.7,+1.2,+0.7$, and $+0.2 \mathrm{~mm}$ relative (anterior) to bregma. Diagrams are modified from ref. [136].

interaction $\left(F_{3.3,53.5}=5.22, \quad \tilde{\varepsilon}=.836, p=.002\right)$. Comparison of the two groups at individual large-reinforcer probabilities demonstrated that AcbC-lesioned rats chose the large/uncertain reinforcer more than shams at 

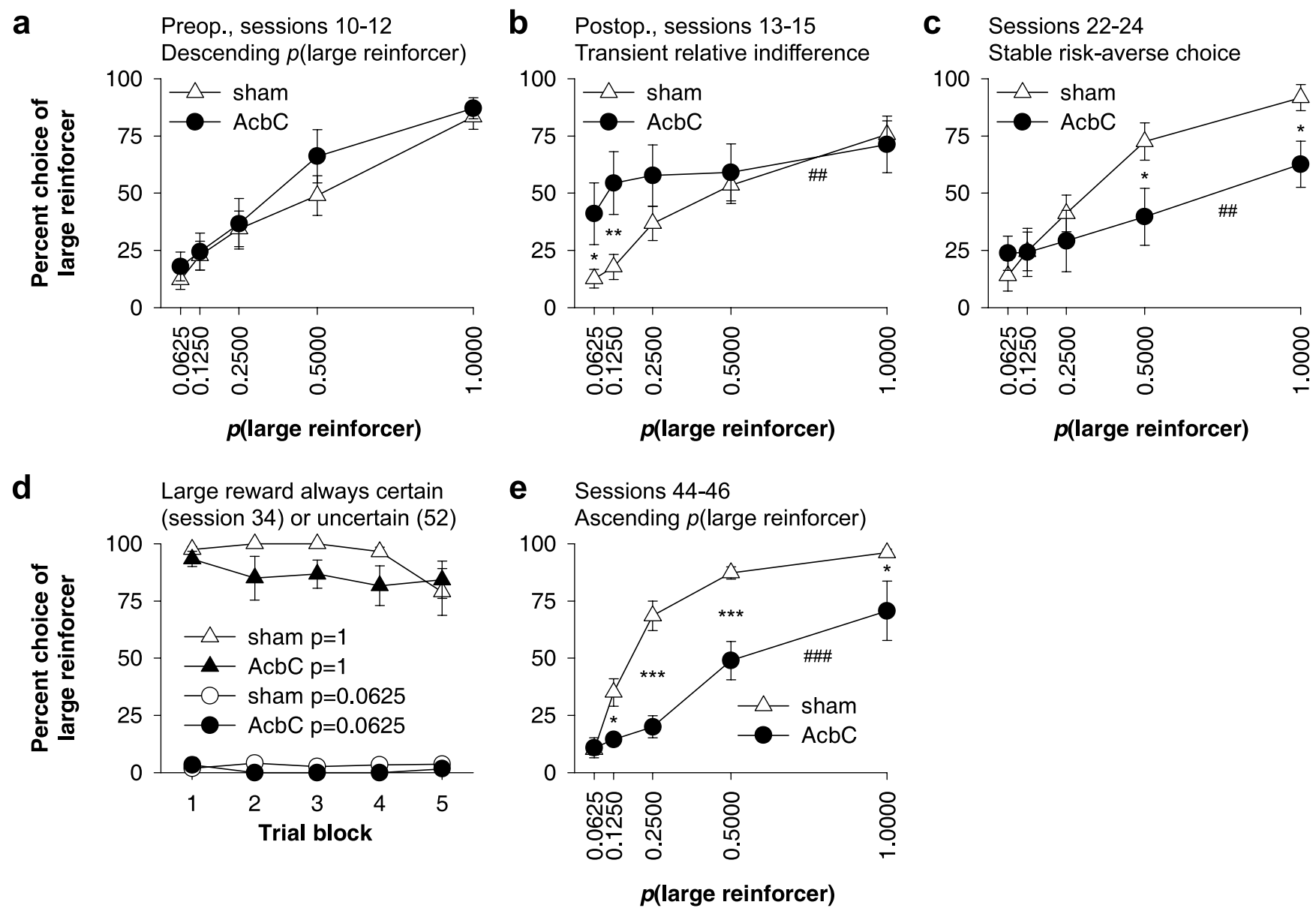

\section{Figure 3}

Choice with probabilistic reinforcement. (a) Preoperative patterns of choice. There were no differences between the groups preoperatively. (b) The first three postoperative sessions. Transiently, AcbC-lesioned rats exhibited relative indifference between the two alternatives; their preference did not differ significantly from $50 \%$ at any large-reinforcer probability. As a result, AcbC-lesioned rats preferred the large, unlikely reinforcer more than shams did when its probability was 0.0625 and 0.125 (\# $p<.0$ I, lesion $\times$ probability interaction; $* p<.05$, $* * p<.01$, comparison to shams at individual probabilities). However, both groups were influenced by the large-reinforcer probability $(p \leq .004)$. (c) The last three postoperative sessions on the same basic task. By this point, AcbC-lesioned rats preferred the large reinforcer less when its probability was 0.5 or I (\#\# $p<.0$ I, interaction; $* p<.05$, simple effects). Again, both groups were influenced by the large-reinforcer probability $(p<.00 \mathrm{I})$. (d) When the 4-pellet reinforcer and the I-pellet reinforcer were both certain, all groups preferred the 4-pellet reinforcer, and when the 4-pellet reinforcer was always very unlikely (delivered with a probability of 0.0625 ) and the I-pellet reinforcer was certain, all groups preferred the I-pellet reinforcer, with no differences between AcbC-lesioned and sham-operated rats. This indicates that both groups discriminated the reinforcers themselves and discriminated their probability of delivery. (e) Choice following further training in which the large-reinforcer probability increased, rather than decreased, across each session. The pattern of choice is similar to $c$, in that AcbC-lesioned rats were risk-averse compared to shams, i.e. less likely to choose the large, unlikely reinforcer (\#\# $p<.00$ I, interaction; $* p<.05$ and $* * * p<.00$ I, simple effects). The similarity to $c$, despite the reversed task order, also indicates that subjects' choice reflected the probabilities in force rather than the order within a session.

$p_{\text {reinforcer }}=0.0625\left(p_{\text {statistical }}=.02\right)$, and at $p_{\text {reinforcer }}=0.125$ $\left(p_{\text {statistical }}=.009\right)$, but did not differ from shams at reinforcer probabilities of $0.25-1\left(p_{\text {statistical }} \geq .158\right)$. Nevertheless, simple effects of probability persisted both in shams
$\left(F_{28,30.9}=32.3, \tilde{\varepsilon}=.702, p<.001\right)$ and in AcbC-lesioned rats $\left(F_{4,20}=5.37, p=.004\right)$. Choice at each $p_{\text {reinforcer }}$ was compared to $50 \%$ (indifference) using post hoc two-tailed one-sample $t$ tests, correcting $p_{\text {statistical values using the }}$ 
Table I: Testing schedule for probabilistic choice task. Subjects were trained and tested according to the schedule shown here. Initial pre- and postoperative testing was conducted with the probability of large reinforcer delivery declining across trial blocks from $I$ to 0.0625 (the steps were $p=1,0.5,0.25,0.125$, and 0.0625 ). Subsequently, subjects were tested alternating between the hungry and sated state (as described in the Methods), before the reinforcement probabilities were manipulated further, as indicated.

\begin{tabular}{llll}
\hline Sessions & Description & Probability (small reward of I pellet) & Probability (large reward of 4 pellets) \\
\hline $1-12$ & Preoperative training (12 sessions) & $p=1$ & $p=1$ to 0.0625 , decreasing \\
- & Surgery and recovery & - & - \\
$13-24$ & Postoperative baseline testing (12 sessions) & $p=1$ & $p=1$ to 0.0625 , decreasing \\
$25-28$ & Satiety tests (4 sessions) & $p=1$ & $p=1$ to 0.0625 , decreasing \\
$29-34$ & Equal probabilities, certain (6 sessions) & $p=1$ & $p=1$ \\
$35-46$ & Increasing probabilities (12 sessions) & $p=1$ & $p=0.0625$ to I, increasing \\
$47-52$ & Large reinforcer always very unlikely (6 sessions) & $p=1$ & $p=0.0625$ \\
\hline
\end{tabular}

Šidák correction for 5 comparisons. For shams, choice differed significantly from $50 \%$ at large-reinforcer probabilities of 0.0625 (when choice of the large reinforcer was less than 50\%), 0.125 (less than 50\%), and 1 (greater than $50 \%$ ) (corrected $\left.p_{\text {statistical }} \leq 0.007\right)$, but for AcbC-lesioned rats, choice did not differ significantly from $50 \%$ at any large-reinforcer probability (corrected $p_{\text {statistical }} \geq 0.81$ ).

\section{Final postoperative choice}

By the final three sessions of the basic task (sessions 2224; see Table 1), the pattern of choice in AcbC-lesioned rats had changed (Figure 3c). Once more, an analysis of choice ratios using the model lesion $n_{2} \times$ ( robability $\left._{5} \times \mathrm{S}\right)$ revealed a lesion $\times$ probability interaction $\left(F_{2.9,46.4}=5.78\right.$, $\tilde{\varepsilon}=.726, p=.002)$. By now, however, AcbC-lesioned rats did not differ from shams with reinforcer probabilities of $0.0625-0.25\left(p_{\text {statistical }} \geq .386\right)$ but chose the large reinforcer less than shams when its probability was 0.5 ( $p_{\text {statis- }}$ tical $=.037)$ and $1\left(p_{\text {statistical }}=.015\right)$. As before, effects of probability persisted both in shams $\left(F_{2.3,24.9}=49.5, \tilde{\varepsilon}=\right.$ $.565, p<.001)$ and in AcbC-lesioned rats $\left(F_{4,20}=9.45, p<\right.$ $.001)$.

\section{Choice when both reinforcers were certain, or both uncertain}

When the large and small reinforcers were both delivered with certainty, AcbC-lesioned and sham-operated rats strongly preferred the large reinforcer; when the small reinforcer was certain and the large reinforcer was consistently unlikely $\left(p_{\text {reinforcer }}=0.0625\right)$, all rats strongly preferred the small reinforcer (Figure 3d). There were no group differences in either case. This indicates that both AcbC-lesioned and sham-operated rats successfully discriminated the large reinforcer from the small reinforcer, and discriminated the certain large reinforcer from the uncertain large reinforcer. Choice ratios from the final sessions of training in these two conditions (sessions 34 and 52; see Table 1) were analysed using the model lesion $_{2} \times\left(\right.$ trial block $\left._{5} \times S\right)$. In the 'certain' condition (session 34$)$, there was no effect of lesion $\left(F_{1,15}=2.54, p=\right.$ .132), no lesion $\times$ block interaction $(F=1.42$, NS $)$, and no effect of trial block $\left(F_{1.5,21.9}=2.12, \tilde{\varepsilon}=.365, p=.154\right)$. Similarly, in the 'uncertain' condition (session 52), there was no effect of lesion $(F=1.35, \mathrm{NS})$, no lesion $\times$ block interaction $(F=1.31, \mathrm{NS})$, and no effect of trial block $(F<$ $1, \mathrm{NS}$ ).

\section{Choice with ascending probabilities}

After rats had been trained with the large-reinforcer probability increasing across the session, choice behaviour was similar to that with the decreasing-probability version of the task used initially, with AcbC-lesioned rats choosing the large/uncertain reinforcer less often than shams (Figure 3e; compare Figure 3c). Choice ratios from sessions 44-46 (see Table 1) were analysed using the model lesion $_{2} \times\left(\right.$ probability $\left._{5} \times S\right)$. As before, there was a lesion $\times$ probability interaction $\left(F_{4,64}=9.29, p<.001\right)$, in addition to main effects of lesion $\left(F_{1,16}=19.5, p<.001\right)$ and probability $\left(F_{4,64}=95.6, p<.001\right)$, and there were strong effects of probability for both AcbC-lesioned rats $\left(F_{1,20}=20.7, p\right.$ $<.001)$ and shams $\left(F_{3.1,34.4}=119.6, \tilde{\varepsilon}=.781, p<.001\right)$. AcbC-lesioned rats differed from shams at reinforcer probabilities of $0.125\left(p_{\text {statistical }}=.033\right), 0.25\left(p_{\text {statistical }}<\right.$ $.001), 0.5\left(p_{\text {statistical }}<.001\right)$, and $1\left(p_{\text {statistical }}=.013\right)$, but not at $p_{\text {reinforcer }}=0.0625\left(p_{\text {statistical }}=.881\right)$.

Postoperative choice: analysis by experienced probability Since the task was genuinely probabilistic, and not pseudorandom, it is possible that the probabilities experienced by subjects differed from the programmed probabilities (although experienced probabilities inevitably tend towards programmed probabilities as the number of trials increases). For example, one subject choosing an uncertain reinforcer at $p_{\text {reinforcer }}=0.5$ for 10 
trials might experience 3 rewarded and 7 unrewarded trials (an experienced probability of 0.3 ), while another might experience 6 rewarded and 4 unrewarded (experienced $p_{\text {reinforcer }}=0.6$ ). To establish whether such effects accounted to any degree for the pattern of choice observed in AcbC-lesioned and sham-operated rats, choice was reanalysed for four sets of sessions (preoperative sessions $10-12$, early postoperative baseline sessions $13-15$, late postoperative baseline sessions 22-24, and sessions 4446 at the end of training on the increasing-probability version of the task; see Figure $4 \mathrm{a}-\mathrm{d}$, compared to the corresponding programmed-probability versions in Figure 3a$\mathrm{c}, \mathrm{e})$. In each case, choice ratios were analysed using the model lesion $_{2} \times($ experienced probability $\mathrm{cov} \times S)$, with the factor $\times$ covariate term included in the model. Experienced probabilities were calculated for all trial types (forced and choice trials), across the sessions concerned.

These analyses confirmed the pattern of results obtained on the basis of programmed probabilities. For the preoperative sessions, as expected, there was a main effect of experienced probability $\left(F_{1.54}=319.1, p<.001\right)$ but no significant terms involving lesion intent $(F s<1, N S)$. For the baseline (decreasing-probability) task, both early (sessions 13-15) and late (sessions 22-24) in the postoperative testing, there was a lesion $\times$ experienced probability interaction (early: $F_{1,54}=25.7, p<.001$; late: $F_{1,54}=20.8$, $p<.001$ ). For the increasing-probability schedule (sessions 44-46), there was no lesion $\times$ experienced probability interaction $\left(F_{1,54}=1.80, p=.185\right)$ but there was a main effect of lesion $\left(F_{1,16.0}=9.36, p=.007\right)$.

\section{Indifference probabilities}

Choice ratios from sham-operated rats on sessions 22-24 (the final 3 postoperative sessions on the basic task; see Table 1) were analysed using four different linear predictors, based either on the probability of delivery of a large reinforcer (given choice of the Large lever), or of the odds against delivery of a large reinforcer, calculated as odds against $=(1-p) / p$. This established that choice patterns were predicted best, in linear fashion, by experienced probabilities (within-subject predictor allowing different slopes for each subject, $r^{2}=0.85$ ) and programmed probabilities $\left(r^{2}=0.84\right)$, rather than by experienced odds $\left(r^{2}=\right.$ $0.61)$ or programmed odds $\left(r^{2}=0.67\right)$. Since optimal behaviour would give choice that was a step function of probability (i.e. it is optimal to choose the small/certain lever whenever the 4-pellet reinforcer is delivered with $p_{\text {re- }}$ inforcer $<0.25$ and to choose the large/uncertain lever whenever $p_{\text {reinforcer }}>0.25$ ), a single-parameter continuous function approximating a step function was also used to predict subjects' choice [the logistic function $y=100 / e^{-(x-}$ $m) / b$ with $y$ as the percentage choice of the large reinforcer, $x$ as the programmed probability, $b=0.01$ as an approximation to $b=0$ and $m$ as the free parameter], but this gave
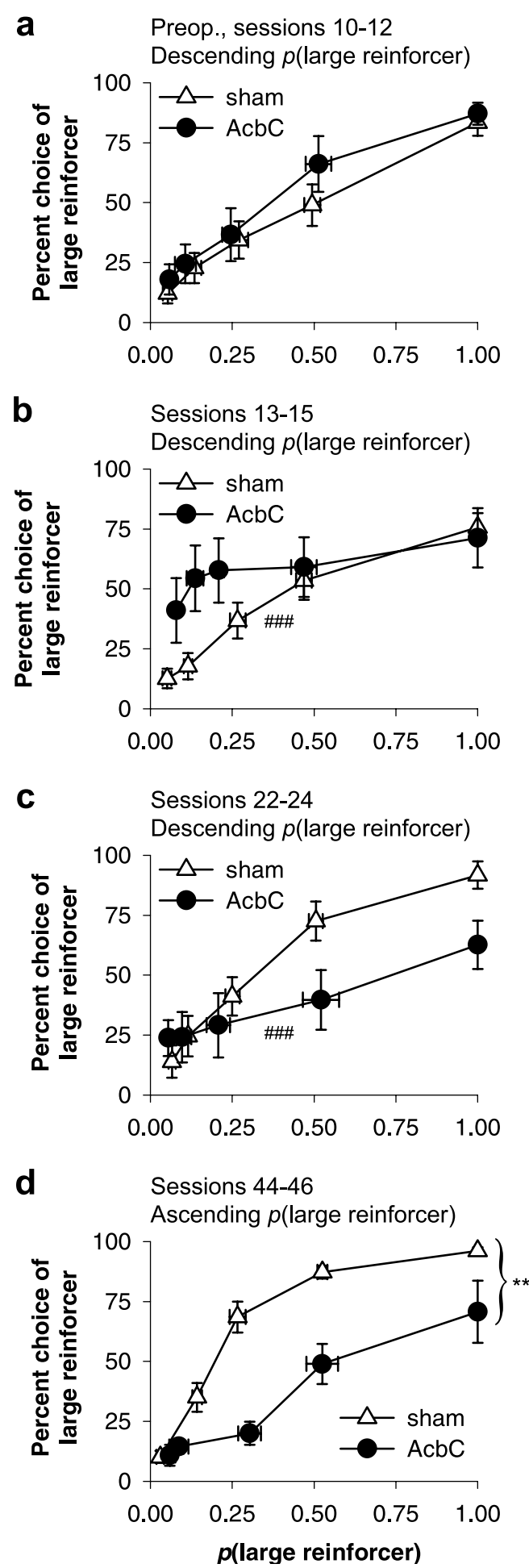

Figure 4

Choice, by experienced probability. Choice, replotted by experienced (as opposed to programmed) large-reinforcer probabilities. Panels a-d correspond to panels a-c/e of the previous figure. The statistical patterns of choice remained the same (\#\# $p<.00$ I, lesion $\times$ experienced delay interaction; $*^{*} p<.01$, main effect of lesion). 
a poor fit ( $r^{2}$ calculated as $\mathrm{SS}_{\text {model }} / \mathrm{SS}_{\text {total }}$ for a nonlinear fit: mean $r^{2}=0.26$; note that individual values of $r^{2}$ can fall outside the range $[0,1]$ when calculated this way for nonlinear models) [40]. Consequently, since choice was best described as a linear function of probability, indifference probabilities were calculated for sham-operated and AcbC-lesioned rats, namely the probability at which rats were equally likely to choose the small/certain and large/ uncertain reinforcers. These were calculated via a linear regression of probability on choice (i.e. a regression in which probability was predicted from choice). This method has the potential to produce nonsensical probabilities for individual rats (if, for example, an individual's curve does not go both above and below the 50\% choice point in a given set of sessions) but is nonetheless useful for group comparison. Experienced large-reinforcer probabilities (across all types of trials) were used, rather than programmed probabilities, though the pattern of results presented below was not altered by the use of programmed probabilities instead.

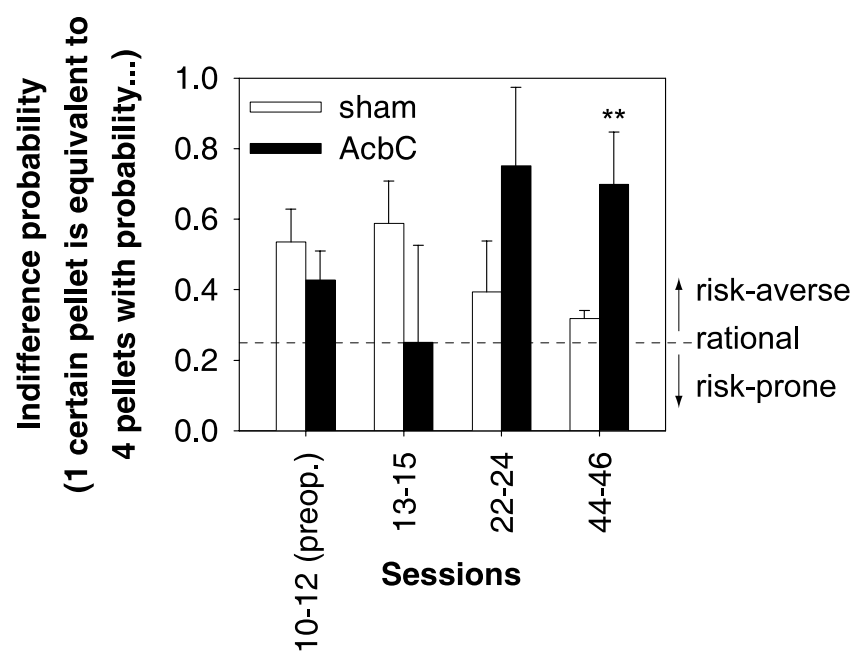

Figure 5

Indifference probabilities. Subjects' behaviour was analysed using a linear regression technique (see text for method of calculation) to estimate the large-reinforcer probability at which they were indifferent between a 4-pellet uncertain large reinforcer and a I-pellet certain small reinforcer. Rational choice, and optimal choice in this task, would be an indifference probability of 0.25 (that is, it is rational to be indifferent between a certain I-pellet reinforcer and a 4pellet reinforcer delivered with a probability of 0.25 ), shown by the dotted line. Lower indifference probabilities imply risk-prone behaviour; higher indifference probabilities imply risk-averse behaviour. Preoperative and successive postoperative indifference probabilities are shown for AcbC-lesioned and sham-operated control rats $(* * p<.01$, difference from controls).
The main finding was that by the end of testing, AcbClesioned rats had higher indifference probabilities $(0.70)$ than sham-operated rats $(0.32)$ (Figure 5$)$ - that is, while sham-operated rats behaved as if indifferent between a 1pellet certain reinforcer and a 4-pellet reinforcer delivered with probability 0.32 (mathematically, an expected number of pellets of $0.32 \times 4=1.28$ ), AcbC-lesioned rats behaved as if indifferent between a 1-pellet certain reinforcer and a 4-pellet reinforcer delivered with probability 0.70 (an expected number of pellets of 2.8). That is, AcbClesioned rats appeared to exhibit risk aversion by the end of testing. The full analysis was as follows. Preoperatively (sessions 10-12), indifference probabilities were $0.43 \pm$ 0.08 (AcbC) and $0.54 \pm 0.09$ (sham); these did not differ $(F<1, \mathrm{NS})$. In the initial postoperative period (sessions 13-15), indifference probabilities were numerically lower in the lesioned group, being $0.25 \pm 0.28$ (AcbC) and 0.59 \pm 0.12 (sham), but indifference probabilities were highly variable in both groups and these did not differ $\left(F_{1,16}=\right.$ $1.76, p=.204$ ). In the later postoperative period (sessions 22-24), indifference probabilities were higher in the lesioned group, being $0.75 \pm 0.22($ AcbC) and $0.39 \pm 0.15$ (sham), though again these did not differ significantly $\left(F_{1,16}=1.90, p=.187\right)$. In the increasing-probability version of the task (sessions 44-46), indifference probabilities were again higher in the lesioned group, being $0.70 \pm$ 0.15 (AcbC) and $0.32 \pm 0.02$ (sham). By this stage the difference was highly significant $\left(F_{1,16}=12.6, p_{\text {statistical }}=\right.$ $.003)$, even if corrected for four comparisons $\left(p_{\text {statistical }}=\right.$ .012) using the Šidák correction.

\section{Omissions and latencies}

Omissions were infrequent and not influenced by reinforcer probability or the lesion. Omission data from the final postoperative baseline sessions (sessions 22-24) were analysed. Overall, omissions (either failures to initiate a trial or to respond to an initiated trial) across all trial types occurred at a rate of $2.9 \pm 0.9 \%$ (sham) and $5.5 \pm$ $1.9 \%$ (AcbC). Omissions on choice trials for the same sessions were analysed using the model lesion $_{2} \times$ $\left(\right.$ probability $\left._{5} \times \mathrm{S}\right)$. There were no effects of lesion $\left(F_{1,16}=\right.$ 1.95 , NS $)$ or probability $\left(F_{1.6,25.2}=2.56, \tilde{\varepsilon}=.394, p=\right.$ $.107)$, and no interaction ( $F=1.04, \mathrm{NS})$. Almost all omissions were failures to initiate a trial (shams $0.9 \%$ of choice trials, AcbC 4.4\%) rather than failures to respond once a trial had been initiated (shams $0.06 \%$ of choice trials, AcbC 0\%).

Initiation latencies on choice trials for sessions 22-24 were analysed in the same manner. They were not affected by the lesion $(F<1, N S)$, nor by the large-reinforcer probability $\left(F_{4,64}=1.41, \mathrm{NS}\right)$, and there was no lesion $\times$ probability interaction $(F<1, N S)$. 
Response latencies were not affected by the lesion, but were affected both by the time in the session, with responding tending to get slower as the session progressed, and by the likelihood of obtaining a large reinforcer, with responding tending to get faster as largereinforcer delivery became more likely. Response latencies on choice trials for sessions 22-24 were analysed using the model lesion ${ }_{2} \times\left(\right.$ trial block $_{5} \times$ choice $\left._{2} \times S\right)$. Response latencies varied across trial blocks: response latencies were initially $0.82 \mathrm{~s}$ (in the first trial block, when the large-reinforcer probability was 1 ) and slowed to $1.1 \mathrm{~s}$ (in the last trial block, when the large-reinforcer probability was $0.0625)\left(F_{3.1,25.1}=2.97, \tilde{\varepsilon}=.785, p=.049\right)$. Latencies were not affected by the lesion, or the lever being chosen, and there were no interactions (maximum $F$ was for response: $F_{1,8}=2.96, p=.124$ ). To establish whether these effects were due to the large-reinforcer probability, or to progressive satiation or the passage of time, data from sessions 44-46 were also analysed, because in these sessions the large-reinforcer probability increased within the session. This time, there was a response $\times$ trial block interaction $\left(F_{4,28}=6.44, p=.001\right)$, with no other terms significant $(F s<1, N S)$. Responding on the small/certain lever initially took $0.71 \mathrm{~s}$ in the first trial block and slowed to $0.95 \mathrm{~s}$ in the last trial block $\left(F_{2.3,24.8}=3.58, \tilde{\varepsilon}=.564, p\right.$ $=.038)$, but responding on the large/uncertain lever initially took $0.97 \mathrm{~s}$ (in the first trial block, when the largereinforcer probability was 0.0625 ) and speeded up to 0.79 $\mathrm{s}$ (in the last trial block, when the large-reinforcer probability was 1$)\left(F_{3.5,38.8}=3.222, \tilde{\varepsilon}=.883, p=.027\right)$.

The lesion did not affect the latency to collect reward. Food collection latencies on rewarded trials were analysed across sessions 22-24, this time including both forced and choice trials to enable an analysis by response and probability. The model lesion ${ }_{2} \times$ (probability $_{5} \times$ response $_{2}$ $\times S)$ was used; this revealed main effects of response $\left(F_{1,13}\right.$ $=13.8, p=.003)$ and probability $\left(F_{2.5,32.8}=3.53, \tilde{\varepsilon}=.631\right.$, $p=.031$ ), but no other significant terms (maximum $F$ was for lesion $\times$ response, $\left.F_{1,13}=3.94, p=.069\right)$. Collection was faster following delivery of the large reinforcer than the small (4.1 versus $5.3 \mathrm{~s}$, respectively), and got slightly slower across the session ( $4.4 \mathrm{~s}$ in the first trial block and $4.9 \mathrm{~s}$ in the last).

\section{Amount of food obtained}

AcbC-lesioned rats obtained less food as a result of their choices (Figure 6a,b). An analysis of the average number of pellets obtained on choice trials in sessions 13-15 using the model lesion ${ }_{2} \times\left(\right.$ probability $\left._{5} \times \mathrm{S}\right)$ revealed a main effect of lesion $\left(F_{1,16}=8.69, p=.009\right)$, as well as an effect of probability $\left(F_{1.9,30.1}=97.5, \tilde{\varepsilon}=.470, p<.001\right)$, but no interaction $(F<1, N S)$. A similar analysis of the final baseline postoperative sessions $22-24$ revealed a lesion $\times$ probability interaction $\left(F_{2.1,33.8}=3.29, \tilde{\varepsilon}=.529\right.$, $p=.047)$ in addition to main effects of lesion $\left(F_{1,16}=14.2\right.$, $p=.002)$ and probability $\left(F_{2.1,33.8}=122.2, \tilde{\varepsilon}=.529, p<\right.$ $.001)$. However, the only probability at which groups significantly differed was $p=1$ (statistical $p=.014$ ); when the large reinforcer probability was $0.0625-0.5$, the two groups did not differ in the amount of food obtained ( $p_{\text {sta- }}$ tistical $\geq .129$ ).

\section{Effects of hunger and satiety on choice}

Alternating between hunger and satiety had no substantial effects on choice (Figure 6b). Choice ratios for sessions 25-28 were analysed using the model lesion ${ }_{2} \times$ (hunger $_{2}$ $\times$ probability $\left._{5} \times \mathrm{S}\right)$. As before, a main effect of probability $\left(F_{2.0,32.6}=38.4, \tilde{\varepsilon}=.510, p<.001\right)$ and a lesion $\times$ probability interaction $\left(F_{2.0,32.6}=4.29, \tilde{\varepsilon}=.510, p=.022\right)$ were present; in addition, there was a marginally significant lesion $\times$ hunger $\times$ probability interaction $\left(F_{4,64}=2.51, p=\right.$ $.05)$. However, an effect of hunger was not detectable in either group alone, either for shams (hunger: $F_{1,11}=2.45$, NS; hunger $\times$ probability: $F_{4,44}=2.18, N S$ ) or for AcbClesioned rats (hunger: $F<1$, NS; hunger $\times$ probability: $F_{4,20}=1.79$, NS). Similarly, the differences between groups persisted both in the hungry (lesion $\times$ probability: $F_{2.6,41.7}=3.66, \tilde{\varepsilon}=.652, p=.024$ ) and the sated (lesion $x$ probability: $F_{2.5,39.3}=4.24, \tilde{\varepsilon}=.615, p=.016$ ) conditions.

\section{Locomotor activity and body mass}

AcbC-lesioned rats were hyperactive and slower to habituate to a novel environment (Figure 7). AcbC-lesioned rats also gained less mass postoperatively. At the time of surgery, the groups did not differ in mass (shams, $357 \pm 4$ g; AcbC, $362 \pm 6$ g; $F<1, N S$ ), but at the end of the experiment AcbC-lesioned rats weighed less than shams (shams, $421 \pm 7 \mathrm{~g}$; AcbC, $358 \pm 10 \mathrm{~g}$; lesion $\times$ time, $F_{1,16}=$ $80.1, p<.001$; simple effect of lesion at final time point: $\left.F_{1,16}=24.5, p<.001\right)$. Both effects are consistent with previous results: AcbC-lesioned rats are known to exhibit locomotor hyperactivity $[22,24,38,41]$ and to weigh less than sham-operated controls $[22,24,41,42]$. They also eat the food used as the maintenance diet in the present study more slowly than sham-operated controls, and eat less of it in a given time, but do not differ in consumption of the sucrose pellets used as reinforcers in the present study $[22,39]$. It is not known whether there are metabolic differences in AcbC-lesioned rats above and beyond the tendency to eat somewhat less and to be hyperactive (though see [43]). However, differences in mass between AcbClesioned and sham-operated rats are also apparent when they have been fed ad libitum ever since the lesion was 
a

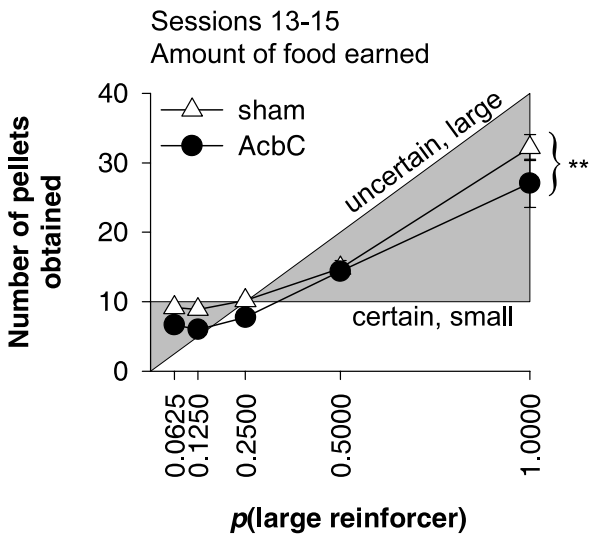

b
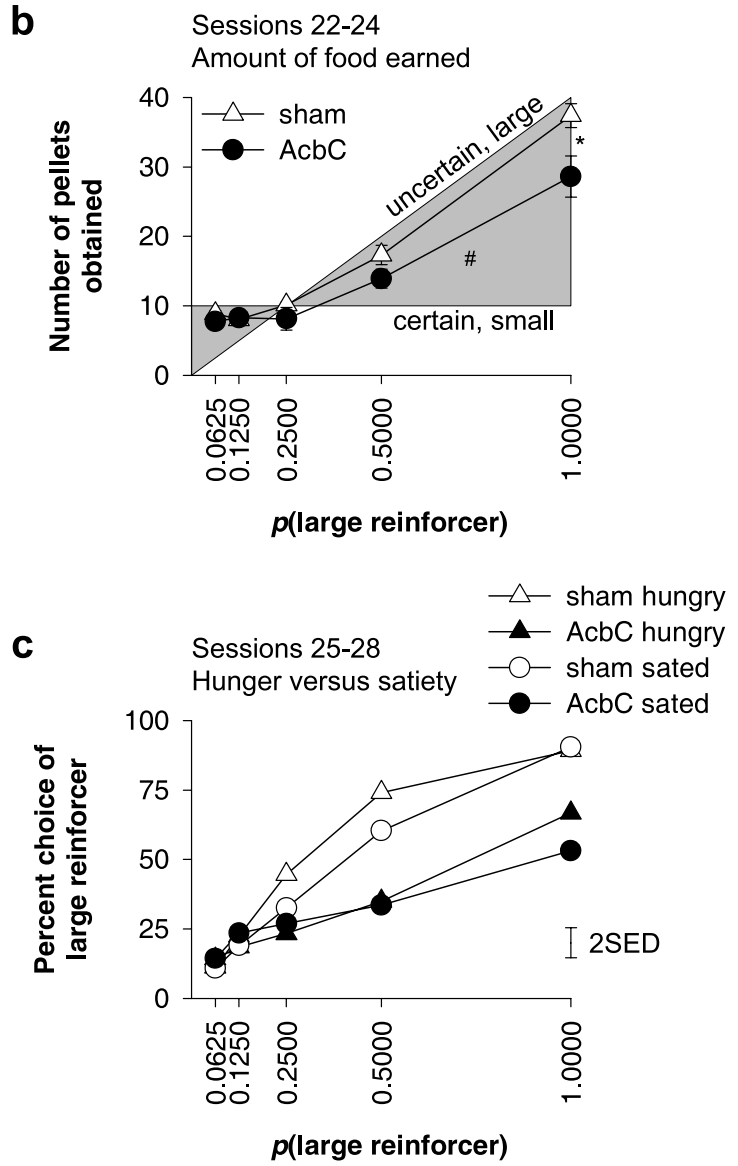

\section{Figure 6}

Amount of food obtained, and effects of satiety on choice. (a) Number of pellets obtained in each trial block; average of the first three postoperative sessions, I3-I5 (** $p<.01$, main effect of lesion). The grey area indicates the expected range of options available to a rat making no omissions: consistent responding on the lever delivering the small, certain reward of a single pellet yields 10 pellets per trial block (horizontal border of the grey area); consistent responding on the lever delivering the large, uncertain reward yields an expected number of pellets that varies with the probability in force (as shown by the diagonal border of the grey area). Optimal behaviour, to maximize the expected amount of food, is to choose the small/certain lever when the large (4-pellet) reinforcer probability is less than 0.25 and to choose the large/uncertain lever when this probability exceeds 0.25. (b) As for (a), but showing data from the final baseline postoperative sessions, 22-24 (\# $p<.05$, lesion $\times$ probability interaction; ${ }^{*} p<.05$, simple effect of lesion). (c) Effects on choice of alternating subjects between states of hunger and satiety. The error bar is twice the SED for the three-way (lesion $\times$ hunger $\times$ probability) interaction. 


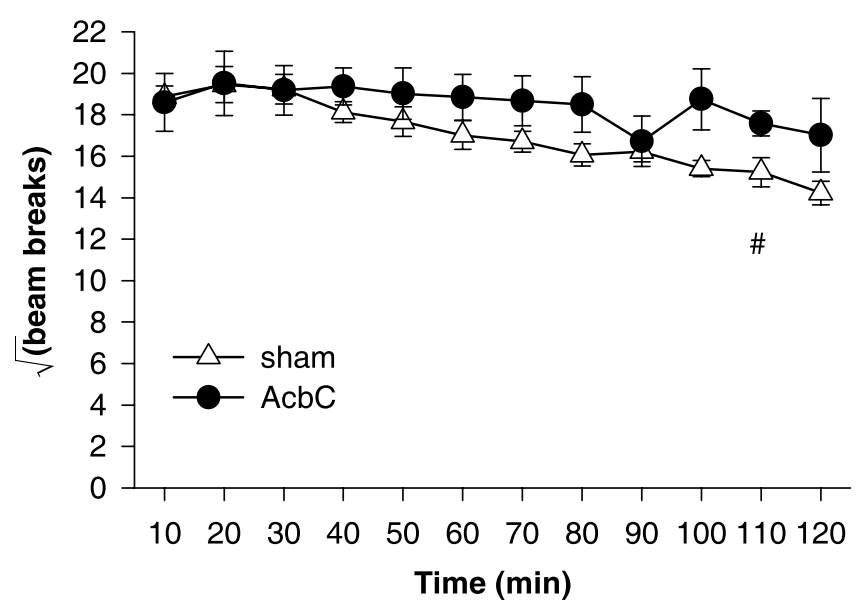

Figure 7

Locomotor activity in a novel environment. AcbClesioned rats were hyperactive compared to sham-operated controls, being slower to habituate to a novel environment. Analysis using the model lesion ${ }_{2} \times\left(\right.$ bin $\left._{12} \times S\right)$ revealed a

lesion $\times$ bin interaction $\left(F_{8.3,133.4}=2.20, \tilde{\varepsilon}=.758, \# p=\right.$ .029), reflecting a difference in habituation between the groups, and a main effect of bin $\left(F_{8.34,133.4}=9.02, p<.001\right)$, reflecting habituation, though there was no main effect of lesion $\left(F_{1,16}=2.24, p=.154\right)$.

made, with AcbC-lesioned rats weighing 88\% as much as sham-operated controls in this situation [39], much as in the present study (85\%). This suggests that the food deprivation regimen maintained the proportional relationship between actual and free-feeding mass similarly in sham-operated and AcbC-lesioned rats.

\section{Discussion}

These results suggest that the AcbC contributes to the selection of uncertain rewards. AcbC-lesioned rats exhibited risk-averse choice: they chose large, uncertain rewards less than sham-operated controls when offered a smaller, certain alternative, even though they showed a strong and unaltered preference for large rewards over small rewards, and for certain rewards over uncertain rewards. By the end of testing, the control group behaved as if indifferent between a single certain food pellet and four pellets delivered with $p=0.32$ (close to the probability of 0.25 that would represent rational indifference), while the AcbClesioned group behaved as if indifferent between a single certain pellet and four pellets delivered with $p=0.70$.

Though these results establish that the lesions used in this study caused this pattern of behaviour, the precise mechanism by which this occurs is unknown: for example, it is possible that the damage caused to structures adjacent to the AcbC, though limited, played a role in this pattern of choice, or that adaptations in other structures consequent upon the lesion were important in the behavioural effects (particularly given that risk aversion was not apparent immediately but emerged with further time and postoperative experience with the task).

\section{Choice in normal subjects}

The dominant model of uncertainty or probability discounting $[1,44-46]$ suggests that subjects calculate a value for each reinforcer, according to its size and other parameters, and discount this by multiplying it by $1 /(1+H \theta)$, where $\theta$ represents the odds against obtaining the reinforcer, $\theta=(1-p) / p$, and $H$ represents an odds discounting parameter that is specific to the individual subject but stable over time for that subject. In this model, value is a hyperbolic function of the odds $\theta$, such a hyperbolic function is supported by empirical research, at least in humans [44,45,47-50]. The present task is not well suited to evaluating such a quantitative model, since in discretetrial schedules it is often the case that animals maximize, or allocate most of their choices to whichever option is the more favourable [51]. However, the behaviour of normal subjects here can be evaluated as to its optimality. In the present task, neither risk aversion nor risk taking is optimal if carried to extremes. Optimal behaviour, to maximize the expected amount of food, is to choose the small/ certain lever when the large (4-pellet) reinforcer probability is less than 0.25 , to choose the large/uncertain lever when the probability exceeds 0.25 , and to be indifferent at $p=0.25$ (i.e. to exhibit a step function in choice). Shams' choice of the large reinforcer behaviour was better described by a linear function of the large-reinforcer probability than by such a step function. Nevertheless, shams' behaviour was reasonably close to the optimal in the most obvious way to measure optimality, namely the amount of food obtained (Figure 6b).

Effects of AcbC lesions in terms of conditioning processes AcbC-lesioned rats chose the large, uncertain reinforcer less often than shams did, but only when a smaller certain reinforcer was available as an alternative; that is, they exhibited risk-averse choice. A number of simple explanations of the present results may be ruled out. For example, it is unlikely that the pattern of choice exhibited by AcbClesioned rats can be explained in terms of perseveration, within a session, on the initially-optimal lever. It might be that animals that perseverated on the lever delivering the small, certain reinforcer, because that lever was initially optimal, would appear to exhibit risk-averse choice in sessions in which the large-reinforcer probability increased across the session (Figure $3 e$ ), but this could not explain the same pattern of choice in sessions in which the same lever was initially suboptimal, i.e. when the large-reinforcer probability decreased across the session (Figure 3c). Furthermore, although AcbC lesions are known to affect 
processes through which Pavlovian conditioned stimuli (CSs) affect behaviour, including Pavlovian-instrumental transfer (PIT), autoshaping, and conditioned reinforcement [38,52-57], there was no Pavlovian CS that was differentially associated with uncertain as opposed to certain reinforcement in this task, so these effects cannot explain the present results. It might be that the AcbC lesion impaired subjects' knowledge of the instrumental actionoutcome contingency specifically for the uncertain outcome. There is some debate about the role of the AcbC in instrumental conditioning (see $[43,58,59]$ ) and goaldirected action, a subset of instrumental conditioning $[58,60,61]$. Manipulation of the AcbC can certainly affect instrumental learning [62-65]. However, the AcbC is not required for simple instrumental conditioning: rats with AcbC lesions acquire lever-press responses on fixed-ratio1 schedules at supernormal levels [24], and rats with Acb or AcbC lesions are fully sensitive to changes in the actionoutcome contingency $[25,53,66]$. However, when acquiring a sequence of random ratio schedules, AcbC-lesioned rats respond somewhat less than sham-operated controls [66], while lesions of the whole Acb made rats respond slightly, though not significantly, less on a similar sequence of random ratio schedules [53]. Random ratio schedules clearly involve probabilistic reinforcement, so these results are consistent with the possibility that the present impairment shown by AcbC-lesioned rats in choosing large, unlikely rewards is due to impaired instrumental conditioning when the outcome is uncertain and, conversely, that the impairment in simple instrumental learning seen previously [66] was specifically a result of the reward uncertainty inherent in a random ratio schedule, given that AcbC-lesioned rats learn instrumental responses normally or supernormally with certain immediate reinforcement [24]. It is also possible that AcbC-lesioned rats represent the instrumental contingency normally with uncertain reward, but simply value the uncertain outcome less and respond less for it accordingly, as discussed next.

\section{Effects of AcbC lesions in terms of probability discounting and reinforcer magnitude sensitivity}

Since the present study required rats to choose between small, certain and large, uncertain rewards, an effect of the lesion to alter the perception of relative reward magnitude might affect choice, just as an alteration in the perception of reward probability might. For example, altering the absolute magnitudes of the reinforcers can affect choice involving probabilistic reinforcement $[67,68]$, as would be predicted if reinforcer 'value' is not simply a linear function of physical magnitude [1]. Specifically, the present results (a tendency for AcbC-lesioned rats to choose the small, certain reinforcer more than shams) could be explained by 'risk aversion' (increased or steeper uncertainty/odds/probability discounting), or if the dif- ference between 1 and 4 pellets was perceived to be smaller by AcbC-lesioned subjects than by shams (due to reduced discrimination between the two reinforcer magnitudes, or perhaps with a normal ability to tell the two apart but with an altered perception of relative value). For example, if a normal subject assigned values of 1 and 4 to the reinforcers, and a lesioned subject assigned values of 1 and 3 to the same reinforcers, then the lesioned subject would be less likely than the sham to choose the large reinforcer when it was made uncertain, even without any primary abnormality in the processing of probability. At first glance, this interpretation would appear to be supported by the observation that AcbC-lesioned rats chose the large reinforcer somewhat less often than shams when it was certain, as well as when it was uncertain. However, several lines of evidence suggest this explanation is not the correct one. When the large and the small reinforcers were both made consistently certain, there were no differences between AcbC-lesioned rats and controls (Figure 3d). Furthermore, other evidence indicates that AcbC lesions do not impair reinforcer magnitude discrimination or the perception of relative reinforcer value. Excitotoxic lesions of the whole Acb do not prevent rats from detecting changes in reward value (induced either by altering the concentration of a sucrose reward or by changing the deprivational state of the subject) [25]. Such lesions also do not impair rats' ability to respond faster when environmental cues predict the availability of larger rewards [26], and nor does inactivation of the Acb with local anaesthetic or blockade of AMPA glutamate receptors in the Acb $[27,69]$; the effects of intra-Acb NMDA receptor antagonists have varied [69-71]. AcbC-lesioned rats can still discriminate large from small rewards $[23,28]$. Similarly, DA depletion of the Acb does not affect the ability to discriminate large from small reinforcers [29-31], and systemic DA antagonists do not affect the perceived quantity of food as assessed in a psychophysical procedure [72]. Furthermore, a recent study found evidence that AcbClesioned rats may even show somewhat enhanced reinforcer magnitude discrimination (or an exaggerated perception of relative value) [24]. Given that reinforcer magnitude discrimination appears to be unimpaired, at worst, by AcbC lesions, the observation in the present study that AcbC-lesioned rats chose the large reinforcer somewhat less often than controls in the task in which large-reinforcer probabilities changed throughout the session is more likely to be explained by within-session generalization $[23,73,74]$ - i.e. that avoidance of the large reinforcer during trial blocks when it was uncertain generalized to trial blocks when it was certain. Together, these findings suggest that the present results are best explained as an effect of AcbC lesions to increase the rate of uncertainty/odds/probability discounting - effectively, a tendency to behave as if an uncertain outcome were less likely than it really is. 


\section{Probability versus delay discounting}

It is known that AcbC lesions affect choice and learning involving delayed reinforcement [22-24]. It has been suggested that delay (or temporal) discounting, the process by which delayed reinforcers lose value, and probability (or odds) discounting, the process by which uncertain reinforcers lose value, reflect the same underlying process [44,45,75-81]. For example, in the present task, choosing the uncertain large reinforcer five times but only obtaining it on the fifth response might be seen as equivalent to a very long delay, on average, between choice of the large reinforcer and its eventual delivery. Alternatively, delays may be seen as entailing the ecological risk of losing the reward during the delay. The failure of AcbC-lesioned rats to choose an uncertain reinforcer (risk aversion, as seen in the stable phase of the present results) and their failure to choose a delayed reinforcer may therefore be explained in the same way. However, there is evidence that time and probability discounting are different and dissociable processes $[1,46,82]$. Most simply, it is not surprising that currency inflation affects human decisions involving delayed but not probabilistic financial reward [83]. Moreover, the absolute magnitude of rewards can have different effects on delayed and probabilistic discounting [46,84,85]. A study looking at human choices in a gambling task found that individuals' propensity to choose rapidly (one, perhaps motoric, measure of delay aversion) and their propensity to bet large amounts of money on uncertain outcomes (a measure of risk taking) represented independent factors [86]. Some studies have found abnormal delay discounting, but not uncertainty discounting, in drug addicts [82,87-89], while gamblers have been observed to discount probabilistic rewards less steeply than controls (i.e. to take risks) without showing differences in delay discounting [8].

\section{Implications for AcbC function and impulsivity}

Impulsivity is multifaceted, reflecting - at the least - individual differences in distinct and dissociable processes involving information gathering, the selection of outcomes, and the inhibition of motor actions [90]. Furthermore, as discussed above, delay discounting and probability discounting may also reflect separate processes. Damage to the AcbC can produce impulsive choice in the sense of an impaired ability to choose delayed rewards [22], in addition to hyperactivity [22,24,38,41], though without impairments in attentional function [91] and without motoric impulsivity as assessed by the stopsignal task [92]. In the context of choice involving uncertain appetitive reinforcement, 'impulsivity' would equate to risk taking (less steep uncertainty discounting or greater willingness to choose unlikely rewards). AcbC lesions, however, produced a risk-averse or conservative pattern of choice in the present study. Clearly, then, AcbC-lesioned rats cannot be characterized as impulsive in all senses. A more appropriate unifying concept would seem to be that the AcbC promotes the selection, and perhaps the salience, of uncertain and delayed rewards - perhaps, in general, of rewards that are not certain, imminent, or present [58]. The AcbC promotes choice of [22] and learning with [24] delayed rewards. It appears to promote the selection of uncertain reinforcers (present results), and this is compatible with human imaging studies showing increased Acb blood flow during the selection of high-risk options [36,37]. The Acb is required for PIT, the process by which Pavlovian CSs signalling reward enhance instrumental responding for those rewards $[52,53]$. It is also required for autoshaping, or locomotor approach to appetitive Pavlovian CSs [38,54-57], and it influences conditioned reinforcement, the process of working for CSs previously paired with reinforcement [38,93-95]. Acb DA also contributes to subjects' motivation to work hard [96-100].

It is not known whether AcbC lesions would produce similar effects on choice involving uncertain aversive events. It would be expected that increased odds/uncertainty/ probability discounting - effectively, a tendency to behave as if an uncertain outcome were less likely than it really is - would produce risk aversion for appetitive outcomes (reduced willingness to choose large, unlikely rewards) but risk proneness for aversive outcomes (increased willingness to choose large, uncertain punishments over small, certain punishments) [1]. In humans, at least, the delay and probability discounting processes appear similar for rewards and losses [46,101].

\section{Relationship to structures and neuromodulator systems innervating the AcbC}

The prefrontal cortex (PFC), which projects heavily to the AcbC [102], is also involved in decision-making under conditions of uncertainty. Humans with orbitofrontal cortex (OFC) or ventromedial PFC damage are impaired on the Iowa gambling task [103-105], in which subjects must learn to differentiate between low-reward, low-risk card decks that yield a net positive outcome and highreward, high-risk decks that yield a net negative outcome, though the precise locus and nature of the deficit seen on this task is debated [106-108]. Choice between small, likely rewards and large, unlikely rewards increases cerebral blood flow in orbital and inferior PFC [109,110], and OFC damage also impairs performance of a task requiring human subjects to choose between two possible outcomes and to bet on their choice, with lesioned subjects deciding slowly and failing to choose the optimal, most likely outcome [111]. Excitotoxic lesions of the OFC make rats less likely than sham-operated controls to choose a large, uncertain reward over a small, certain reward [112]; OFC-lesioned rats had lower indifference odds (higher indifference probabilities; steeper uncertainty discounting) and exhibited risk-averse choice, just 
like the AcbC-lesioned subjects in the present study. There is direct evidence that OFC lesions do alter sensitivity to the relative magnitudes of the two rewards [113], as does OFC DA depletion [114], but the effects on uncertainty discounting are present in addition to those on reinforcer magnitude sensitivity [115].

The Acb is also innervated by the a number of neuromodulator systems, including the serotonin (5-hydroxytryptamine; 5-HT) system [116]. Although manipulations of 5-HT influence choice involving delayed reinforcement, there is less evidence that they influence choice involving uncertainty and risk. Correlational studies have indicated that low cerebrospinal fluid (CSF) levels of the 5-HT metabolite 5-hydroxyindoleacetic acid (5-HIAA) are associated with risk taking in monkeys [117] and impulsive aggression, violence, and suicide in humans [118122]. Forebrain 5-HT depletion tends to steepen temporal (delay) discounting (reviewed briefly by [28]); however, it does not appear to influence choice involving probabilistic reinforcement. Dietary tryptophan depletion [123125] decreases levels of 5-HT metabolites in CSF, an indirect indicator of brain 5-HT levels, but has not been shown to affect probability discounting in humans [126,127]; similarly, forebrain 5-HT depletion in rats does not affect choice between small, certain rewards and large, uncertain rewards [128]. The AcbC also receives a substantial DA innervation, and DA neurons respond to reward prediction errors [18-21]. Although systemic D2-type DA receptor antagonists can induce impulsive choice involving delayed reinforcement [129], this effect may not occur in the Acb [130], the response of DA neurons specifically to reward uncertainty is debated [32-34], and little is known of the role of DA in choice involving uncertain rewards. Systemic noradrenergic (NA) blockade has also been shown to affect decision-making under uncertainty in humans, by reducing the discrimination between magnitudes of different losses when the probability of losing was high [131], though NA reuptake inhibition has not been shown to affect the Iowa gambling task [132]. However, the Acb does not receive a substantial NA innervation [133].

\section{Conclusion}

We have shown that excitotoxic lesions of the AcbC induce risk-averse choice in rats. AcbC lesions did not prevent rats from discriminating a large reward from a small reward, or a certain reward from an uncertain reward. However, when offered the choice between a small/certain reward and a large/uncertain reward, AcbC-lesioned rats showed a reduced preference for the large/uncertain reward (compared to sham-operated controls) in their final pattern of postoperative choice. AcbC-lesioned rats exhibited a tendency to behave as if an uncertain outcome were less likely than was really the case. Together with pre- vious studies, these results suggest that the AcbC contributes to reinforcement and choice particularly when the reinforcer is temporally distant or uncertain.

\section{Methods}

\section{Subjects and housing conditions}

The subjects were 24 male Lister hooded rats (HarlanOlac UK Ltd) housed in a temperature-controlled room (minimum $22^{\circ} \mathrm{C}$ ) under a $12: 12 \mathrm{~h}$ reversed light-dark cycle (lights off 07:30 to 19:30). Subjects were approximately 15 weeks old on arrival at the laboratory and were given a minimum of a week to acclimatize, with free access to food, before experiments began. Preoperatively, subjects were housed in pairs; postoperatively, they were housed individually. Experiments took place between 09:00 and 21:00, with individual subjects being tested at a consistent time of day. Subjects had free access to water. During behavioural testing, subjects were fed 15-16 g/ day, an amount that maintains $\sim 85-90 \%$ of free-feeding mass in normal male Lister hooded rats (the free-feeding mass being a steadily-increasing quantity at this age). Feeding occurred in the home cages at the end of the experimental day. As it was possible for subjects to earn substantial amounts of food in the behavioural tasks, the amount of food actually earned was taken into account when feeding with the maintenance diet in the home cages. All procedures were subject to UK Home Office approval (Project Licence 80/1767) under the Animals (Scientific Procedures) Act 1986.

\section{Behavioural apparatus}

Behavioural testing was conducted in one of two types of operant chamber of identical configuration (from Med Associates Inc., Georgia, Vermont, USA, or Paul Fray Ltd, Cambridge, UK). Each chamber was fitted with a $2.8 \mathrm{~W}$ overhead house light and two retractable levers on either side of an alcove fitted with an infrared photodiode to detect head entry and a $2.8 \mathrm{~W}$ lightbulb ('traylight'). Sucrose pellets ( $45 \mathrm{mg}$, Rodent Diet Formula P, Noyes, Lancaster, New Hampshire, USA) could be delivered into the alcove. The chambers were enclosed within soundattenuating boxes fitted with fans to provide air circulation. The apparatus was controlled by software written by RNC in C++ [134] using the Whisker control system [135]. Equal numbers of subjects were trained in the two brands of operant chamber (12 in each type). Individual subjects were always tested in the same operant chamber.

\section{Initial training}

Rats were first trained to press the left lever for single pellets on a fixed-ratio-1 schedule, in 30-min sessions, until they had obtained a total of 100 pellets. This procedure was repeated for the right lever. They were then trained to nosepoke to initiate presentation of a lever in discrete trials. Each session began with the levers retracted and the 
operant chamber in darkness. Every $40 \mathrm{~s}$, a trial began with illumination of the houselight and the traylight. The subject was required to make a nosepoke response within $10 \mathrm{~s}$, or the current trial was aborted and the chamber returned to darkness. If the subject nosepoked within this time limit, the traylight was extinguished and a single lever presented. If the rat failed to respond on the lever within $10 \mathrm{~s}$, the lever was retracted and the chamber darkened, but if it responded, the houselight was switched off, a single pellet was delivered immediately and the traylight was illuminated until the rat collected the pellet (or a 10s collection time limit elapsed, whereupon the chamber was darkened). In every pair of trials, the left lever was presented once and the right lever once, though the order within the pair of trials was random. Rats were trained to a criterion of 60 successful trials in one hour (the maximum possible with a 40-s period being 90). They then proceeded to the full task.

\section{Probabilistic choice task}

The task was based on delayed reinforcement choice tasks that have been described before $[73,74]$. The session began in darkness with the levers retracted; this was designated the intertrial state. Trials began at 40-s intervals; the format of a single trial is shown in Figure 2. Each trial began with the illumination of the houselight and the traylight. The rat was required to make a nosepoke response, ensuring that it was centrally located at the start of the trial (latency to poke was designated the initiation latency). If the rat did not respond within $10 \mathrm{~s}$ of the start of the trial, the operant chamber was reset to the intertrial state until the next trial began and the trial was scored as an omission. If the rat was already nosepoking when the trial began, the next stage followed immediately. Upon a successful nosepoke, the traylight was extinguished and one or both levers were extended. One lever was designated the Large/Uncertain lever, the other the Small/Certain lever (counterbalanced left/right). The latency to choose a lever was recorded. (If the rat did not respond within $10 \mathrm{~s}$ of lever presentation, the chamber was reset to the intertrial state until the next trial and the trial was scored as an omission.) When a lever was chosen, both levers were retracted and the houselight was switched off. Choice of the Small lever caused the certain delivery of one pellet; choice of the Large lever caused the delivery of 4 pellets with a particular probability (see below). When reinforcement was delivered, the traylight was switched on. Multiple pellets were delivered $0.5 \mathrm{~s}$ apart. If the rat collected the pellets before the next trial began, then the traylight was switched off and the time from delivery of the first pellet until a nosepoke occurred was recorded as the collection latency. If the rat did not collect the food within $10 \mathrm{~s}$ of its delivery, the operant chamber entered the intertrial state, though collection latencies were still recorded up to the start of the next trial. The chamber was then in the intertrial state and remained so until the next trial. There was no mechanism to remove uneaten pellets, but failure to collect the reward was an extremely rare event. The large-reinforcer probability was varied systematically across the session as follows. A session consisted of 5 blocks, each comprising 16 trials in which only one lever was presented ( 8 trials for each lever, randomized in pairs) followed by 10 free-choice trials. The probability that the large reinforcer was delivered, given that the Large lever had been chosen ( $\left.p_{\text {reinforcer }}\right)$, varied across blocks: it was initially $1,0.5,0.25,0.125$, and 0.0625 , respectively, for each block. As trials began every $40 \mathrm{~s}$ and there were 130 trials per session, the total session length was $\sim 87$ minutes; subjects received one session per day. Choice ratios (percentage choice of the large reinforcer, for each trial block) were calculated using only choice trials on which the subject responded.

\section{Excitotoxic lesions of the AcbC}

Subjects were anaesthetized with Avertin (2\% w/v 2,2,2tribromoethanol, $1 \% \mathrm{w} / \mathrm{v} 2$-methylbutan-2-ol, and $8 \% \mathrm{v} /$ $\mathrm{v}$ ethanol in phosphate-buffered saline, sterilized by filtration, $10 \mathrm{ml} / \mathrm{kg}$ intraperitoneally) and placed in a Kopf or Stoelting stereotaxic frame (David Kopf Instruments, Tujunga, California, USA; Stoelting Co., Wood Dale, Illinois, USA) fitted with atraumatic ear bars. The skull was exposed and a dental drill was used to remove the bone directly above the injection sites. The dura mater was broken with the tip of a hypodermic needle, avoiding damage to underlying venous sinuses. Excitotoxic lesions of the AcbC were made by injecting $0.5 \mu \mathrm{l}$ of $0.09 \mathrm{M}$ quinolinic acid (Sigma, UK) per side through a glass micropipette at coordinates $1.2 \mathrm{~mm}$ anterior to bregma, $\pm 1.8 \mathrm{~mm}$ from the midline, and $7.1 \mathrm{~mm}$ below the skull surface at bregma; the incisor bar was $3.3 \mathrm{~mm}$ below the interaural line [136]. The toxin had been dissolved in $0.1 \mathrm{M}$ phosphate buffer (composition $0.07 \mathrm{M} \mathrm{Na}_{2} \mathrm{HPO}_{4}, 0.028 \mathrm{M}$ $\mathrm{NaH}_{2} \mathrm{PO}_{4}$ in double-distilled water, sterilized by filtration) and adjusted with $\mathrm{NaOH}$ to a final $\mathrm{pH}$ of 7.2-7.4. Toxin was injected over $3 \mathrm{~min}$ and the micropipette was left in place for 2 min following injections. Sham lesions were made in the same manner except that vehicle was infused. At the end of the operation, animals were given $15 \mathrm{ml} / \mathrm{kg}$ of sterile $5 \% \mathrm{w} / \mathrm{v}$ glucose, $0.9 \% \mathrm{w} / \mathrm{v}$ sodium chloride intraperitoneally. They were given a week to recover, with free access to food, and were handled regularly. Any instances of postoperative constipation were treated with liquid paraffin orally and rectally. At the end of this period, food restriction commenced or was resumed.

\section{Postoperative testing}

Subjects were trained preoperatively and tested postoperatively according to the schedule shown in Table 1 . In the basic task, used for preoperative training, the probability 
of large reinforcer delivery declined across trial blocks from 1 to 0.0625 (in the order $1,0.5,0.25,0.125$, $0.0625)$. After subjects had been tested postoperatively for 12 sessions on this schedule, satiety tests were given, to establish the effect of varying primary motivational state on preference for probabilistic reinforcement. Subjects were tested for 4 sessions while alternating between hungry and sated states on consecutive days in counterbalanced fashion (half the subjects experienced hungry and sated days in the order HSHS, and half in the order SHSH). Following a 'hungry' session, animals were placed on free food (maintenance diet) until the start of the next day's 'sated' session, at which time the food was again removed for the 'hungry' session to follow. The comparison was therefore between food deprivation for $\sim 22 \mathrm{~h}$ and satiety. Next, subjects were returned to the hungry state and tested for 6 sessions on a schedule in which both the large and small reinforcer were delivered with certainty. Next, the element of uncertainty was reintroduced for another 12 sessions, but this time the probability of large reinforcer delivery (given that the Large lever had been chosen) increased across blocks from 0.0625 to 1 (in the order $0.0625,0.125,0.25,0.5,1)$. Finally, subjects were tested for 6 sessions with the large reinforcer always being very unlikely $(p=0.0625)$, with the small reinforcer remaining certain.

\section{Locomotor activity in a novel environment}

Locomotor activity was measured in wire mesh cages, 25 $(\mathrm{W}) \times 40(\mathrm{D}) \times 18(\mathrm{H}) \mathrm{cm}$, each equipped with a water bottle and two horizontal photocell beams situated $1 \mathrm{~cm}$ from the floor that enabled movements along the long axis of the cage to be registered. Subjects were placed in these cages, which were initially unfamiliar to them, and their activity was recorded for $2 \mathrm{~h}$. All animals were tested in the food-deprived state. Locomotor hyperactivity and reduced body mass gain have previously been part of the phenotype of AcbC-lesioned rats, though without alterations in the consumption of the reinforcer used in the present experiments $[22,24,38,39,41]$.

\section{Histology}

Rats were deeply anaesthetized with pentobarbitone sodium $(200 \mathrm{mg} / \mathrm{ml}$, minimum of $1.5 \mathrm{ml}$ i.p.) and perfused transcardially with $0.01 \mathrm{M}$ phosphate-buffered saline (PBS) followed by $4 \%$ paraformaldehyde in PBS. Their brains were removed and postfixed in paraformaldehyde before being dehydrated in $20 \%$ sucrose for cryoprotection. The brains were sectioned coronally at $60 \mu \mathrm{m}$ thickness on a freezing microtome and every third section mounted on chromium potassium sulphate/gelatincoated glass microscope slides and allowed to dry. Sections were passed through a series of ethanol solutions of descending concentration (3 minutes in each of $100 \%$, $95 \%$, and $70 \% \mathrm{v} / \mathrm{v}$ ethanol in water) and stained for $\sim 5$ min with cresyl violet. The stain comprises $0.05 \% \mathrm{w} / \mathrm{v}$ aqueous cresyl violet (Raymond A. Lamb Ltd, Eastbourne, UK), $2 \mathrm{mM}$ acetic acid, and $5 \mathrm{mM}$ formic acid in water. Following staining, sections were rinsed in water and 70\% ethanol before being differentiated in 95\% ethanol. Finally, they were dehydrated and delipidated in 100\% ethanol and Histoclear (National Diagnostics, UK) before being cover-slipped using DePeX mounting medium (BDH, UK) and allowed to dry. The sections were used to verify lesion placement and assess the extent of lesioninduced neuronal loss. Lesions were detectable as the absence of visible neurons (cell bodies of the order of 100 $\mu \mathrm{m}$ in diameter with a characteristic shape and appearance), often associated with a degree of tissue collapse (sometimes with consequent ventricular expansion when the lesion was adjacent to a ventricle) and gliosis (visible as the presence of smaller, densely-staining cells).

\section{Data analysis}

Data collected by the chamber control programs were imported into a relational database (Microsoft Access 97) for case selection and analysed with SPSS 11. Figures were created with SigmaPlot 2001/v7 and Adobe Illustrator 8. All graphs show group means and error bars are \pm 1 standard error of the mean (SEM) unless otherwise stated. Count data (e.g. locomotor activity counts), for which variance increases with the mean, were subjected to a squareroot transformation prior to any analysis [137]. Homogeneity of variance was verified using Levene's test [138]. General linear models are described as dependent variable $=A_{2} \times B_{c o v} \times\left(C_{5} \times D_{c o v} \times S\right)$ where $\mathrm{A}$ is a between-subjects factor with two levels, $\mathrm{B}$ is a between-subjects covariate, $\mathrm{C}$ is a within-subjects factor with five levels, and D is a within-subjects covariate; $\mathrm{S}$ denotes subjects in designs involving within-subjects factors [139]. For repeated measures analyses, Mauchly's test of sphericity of the covariance matrix was applied [140] and the degrees of freedom corrected to more conservative values by multiplying them by the Huynh-Feldt epsilon $\tilde{\varepsilon}$ for any terms involving factors in which the sphericity assumption was violated [141]. Where multiple comparisons were conducted post hoc following a significant overall ANOVA effect for a factor with more than three levels, $p$ values were corrected using the Šidák correction [142], in which $p_{\text {corrected }}=1-(1$ - $\left.p_{\text {uncorrected }}\right)^{n}$ for $n$ comparisons.

\section{List of abbreviations used}

5-HIAA, 5-hydroxyindoleacetic acid

5-HT, 5-hydroxytryptamine (serotonin)

Acb, nucleus accumbens

AcbC, nucleus accumbens core 
AcbSh, nucleus accumbens shell

ANOVA, analysis of variance

CS, conditioned stimulus

CSF, cerebrospinal fluid

DA, dopamine

$\tilde{\varepsilon}$, Huynh-Feldt epsilon

h, hour

i.p., intraperitoneal

min, minute

NA, noradrenaline

OFC, orbitofrontal cortex

p, probability

$p_{\text {reinforcer }}$ probability of delivery of the large reinforcer after it had been chosen

$p_{\text {statistical }}$ statistical $p$ value (probability of obtaining the observed data, or results more extreme, were the null hypothesis to be true)

PBS, phosphate-buffered saline

PIT, Pavlovian-instrumental transfer

PFC, prefrontal cortex

$r^{2}$, proportion of variance explained

SED, standard error of the difference between means

SEM, standard error of the mean

SS, sum of squares (sum of squared deviations)

$\mathrm{v} / \mathrm{v}$, volume per unit volume

$\mathrm{w} / \mathrm{v}$, weight per unit volume

$[x, y)$, a range that includes $x$ but not $y$

\section{Authors' contributions}

RNC conceived and designed the studies, supervised NJH, wrote the software, performed the surgery, and drafted the manuscript. NJH participated in the design of the studies, and tested the animals. The work contributed to NJH's B.A. degree. Both authors analysed the results, and read and approved the final manuscript.

\section{Acknowledgements}

Supported by a Wellcome Trust programme grant (to Trevor W. Robbins, Barry J. Everitt, Angela C. Roberts, and Barbara J. Sahakian); conducted within the UK Medical Research Council (MRC) Behavioural and Clinical Neuroscience Centre, Cambridge. We thank three anonymous referees for their helpful comments. Competing interests: none declared.

\section{References}

I. Ho MY, Mobini S, Chiang TJ, Bradshaw CM, Szabadi E: Theory and method in the quantitative analysis of "impulsive choice" behaviour: implications for psychopharmacology. Psychopharmacology 1999, 146:362-372.

2. Evenden JL: Impulsivity: a discussion of clinical and experimental findings. Journal of Psychopharmacology 1999, 13:180-192.

3. Eysenck SGB: The 17: development of a measure of impulsivity and its relationship to the superfactors of personality. In The impulsive client: theory, research and treatment Edited by: McCown WG, Johnson JL and Shure MB. Washington DC, American Psychological Association; 1993.

4. Daruna JH, Barnes PA: A neurodevelopmental view of impulsivity. In The impulsive client: theory, research and treatment Edited by: McCown WG, Johnson JL and Shure MB. Washington, DC, American Psychological Association; 1993.

5. APA: Diagnostic and Statistical Manual of Mental Disorders, fourth edition, text revision (DSM-IV-TR). Washington DC, American Psychiatric Association; 2000.

6. Roy A, Dejong J, Linnoila M: Extraversion in pathological gamblers: correlates with indices of noradrenergic function. Archives of General Psychiatry 1989, 46:679-68I.

7. Coccaro EF, Siever LJ): The neuropsychopharmacology of personality disorders. In Psychopharmacology: The Fouth Generation of Progress Volume 1567-1579. Edited by: Bloom FE and Kupfer DJ. New York, American College of Neuropsychopharmacology / Raven Press [ http://www.acnp.org/content-32.html ]; 1995.

8. Holt DD, Green L, Myerson J: Is discounting impulsive?. Evidence from temporal and probability discounting in gambling and non-gambling college students. Behav Processes 2003, 64:355-367.

9. OUP: New Shorter Oxford English Dictionary. Oxford, UK, Oxford University Press; 1997.

10. Knutson B, Adams CM, Fong GW, Hommer D: Anticipation of increasing monetary reward selectively recruits nucleus accumbens. J Neurosci 200I, $21:$ RCI59.

II. Breiter HC, Aharon I, Kahneman D, Dale A, Shizgal P: Functional imaging of neural responses to expectancy and experience of monetary gains and losses. Neuron 2001, 30:619-639.

12. Schultz W, Tremblay L, Hollerman JR: Reward processing in primate orbitofrontal cortex and basal ganglia. Cereb Cortex 2000, 10:272-284.

13. Miyazaki K, Mogi E, Araki N, Matsumoto G: Reward-quality dependent anticipation in rat nucleus accumbens. Neuroreport 1998, 9:3943-3948.

14. Schultz W, Apicella P, Scarnati E, Ljungberg T: Neuronal activity in monkey ventral striatum related to the expectation of reward. Journal of Neuroscience 1992, I 2:4595-4610.

15. Bjork JM, Knutson B, Fong GW, Caggiano DM, Bennett SM, Hommer DW: Incentive-elicited brain activation in adolescents: similarities and differences from young adults. I Neurosci 2004, 24:1793-1802.

16. Martin $\mathrm{PD}$, Ono $\mathrm{T}$ : Effects of reward anticipation, reward presentation, and spatial parameters on the firing of single neurons recorded in the subiculum and nucleus accumbens of freely moving rats. Behav Brain Res 2000, I | 6:23-38.

17. Cromwell HC, Schultz W: Effects of expectations for different reward magnitudes on neuronal activity in primate striatum. J Neurophysiol 2003, 89:2823-2838.

18. Schultz W, Dickinson A: Neuronal coding of prediction errors. Annual Review of Neuroscience 2000, 23:473-500. 
19. Schultz W, Dayan P, Montague PR: A neural substrate of prediction and reward. Science 1997, 275:1593-1599.

20. Schultz W: Predictive reward signal of dopamine neurons. J Neurophysiol 1998, 80: I-27.

21. Schultz W, Tremblay L, Hollerman JR: Reward prediction in primate basal ganglia and frontal cortex. Neuropharmacology 1998, 37:42I-429.

22. Cardinal RN, Pennicott DR, Sugathapala CL, Robbins TW, Everitt BJ: Impulsive choice induced in rats by lesions of the nucleus accumbens core. Science 200I, 292:2499-250I.

23. Cardinal RN, Robbins TW, Everitt BJ: Choosing delayed rewards: perspectives from learning theory, neurochemistry, and neuroanatomy. In Choice, Behavioral Economics and Addiction Edited by: Heather $N$ and Vuchinich RE. Oxford, Elsevier; 2003:183-213, 217-218.

24. Cardinal RN, Cheung THC: Nucleus accumbens core lesions retard instrumental learning and performance with delayed reinforcement in the rat. BMC Neuroscience 2005, 6:9.

25. Balleine B, Killcross S: Effects of ibotenic acid lesions of the nucleus accumbens on instrumental action. Behavioural Brain Research 1994, 65:181-193.

26. Brown VJ, Bowman EM: Discriminative cues indicating reward magnitude continue to determine reaction time of rats following lesions of the nucleus accumbens. European Journal of Neuroscience 1995, 7:2479-2485.

27. Giertler C, Bohn I, Hauber W: Transient inactivation of the rat nucleus accumbens does not impair guidance of instrumental behaviour by stimuli predicting reward magnitude. Behav Pharmacol 2004, 15:55-63.

28. Cardinal RN, Winstanley CA, Robbins TW, Everitt BJ: Limbic corticostriatal systems and delayed reinforcement. Annals of the New York Academy of Sciences 2004, 1021 :33-50.

29. Salamone JD, Cousins MS, Bucher S: Anhedonia or anergia? Effects of haloperidol and nucleus accumbens dopamine depletion on instrumental response selection in a T-maze cost/benefit procedure. Behavioural Brain Research 1994, 65:22I-229.

30. Salamone JD, Wisniecki A, Carlson BB, Correa M: Nucleus accumbens dopamine depletions make animals highly sensitive to high fixed ratio requirements but do not impair primary food reinforcement. Neuroscience 200I, 105:863-870.

31. Cousins MS, Atherton A, Turner L, Salamone JD: Nucleus accumbens dopamine depletions alter relative response allocation in a T-maze cost/benefit task. Behavioural Brain Research 1996, 74:189-197.

32. Fiorillo $C D$, Tobler PN, Schultz W: Discrete coding of reward probability and uncertainty by dopamine neurons. Science 2003, 299: 1898-1902.

33. Tobler PN, Fiorillo CD, Schultz W: Adaptive coding of reward value by dopamine neurons. Science 2005, 307:1642-1645.

34. Niv $Y$, Duff MO, Dayan P: Dopamine, uncertainty and TD learning. Behavioral and Brain Functions 2005, I:6.

35. Aron AR, Shohamy D, Clark J, Myers C, Gluck MA, Poldrack RA: Human midbrain sensitivity to cognitive feedback and uncertainty during classification learning. J Neurophysiol 2004, 92: II44-II 52.

36. Ernst M, Nelson EE, McClure EB, Monk CS, Munson S, Eshel N, Zarahn E, Leibenluft E, Zametkin A, Towbin K, Blair J, Charney D Pine DS: Choice selection and reward anticipation: an fMRI study. Neuropsychologia 2004, 42:1585-1597.

37. Matthews SC, Simmons AN, Lane SD, Paulus MP: Selective activation of the nucleus accumbens during risk-taking decision making. Neuroreport 2004, 15:2/23-2/27.

38. Parkinson JA, Olmstead MC, Burns LH, Robbins TW, Everitt B]: Dissociation in effects of lesions of the nucleus accumbens core and shell on appetitive Pavlovian approach behavior and the potentiation of conditioned reinforcement and locomotor activity by d-amphetamine. Journal of Neuroscience 1999, 19:240|-24II.

39. Cardinal RN: Neuropsychology of reinforcement processes in the rat [unpublished PhD thesis; www.pobox.com/ rudolf/ publications/200I/PhD ]. Cambridge, UK, University of Cambridge; 2001.

40. Cameron AC, Windmeijer FAG: An R-squared measure of goodness of fit for some common nonlinear regression models. Journal of Econometrics 1997, 77:329-342.
4I. Maldonado-Irizarry CS, Kelley AE: Excitotoxic lesions of the core and shell subregions of the nucleus accumbens differentially disrupt body-weight regulation and motor activity in the rat. Brain Research Bulletin 1995, 38:55I-559.

42. Parkinson JA: Limbic corticostriatal circuitry underlying Pavlovian associative learning [unpublished PhD thesis]. Cambridge, UK, University of Cambridge; 1998.

43. Kelley AE: Ventral striatal control of appetitive motivation: role in ingestive behavior and reward-related learning. Neurosci Biobehav Rev 2004, 27:765-776.

44. Rachlin H, Raineri A, Cross D: Subjective probability and delay. Journal of the Experimental Analysis of Behavior 1991, 55:233-244.

45. Rachlin H, Logue AW, Gibbon J, Frankel M: Cognition and behavior in studies of choice. Psychological Review 1986, 93:33-45.

46. Green L, Myerson J: A discounting framework for choice with delayed and probabilistic rewards. Psychol Bull 2004, 130:769-792.

47. Rachlin $\mathrm{H}$, Siegel $\mathrm{E}$ : Temporal patterning in probabilistic choice. Organizational Behavior and Human Decision Processes 1994, 59:16I-176.

48. Rachlin H, Brown J, Cross D: Discounting in judgments of delay and probability. Journal of Behavioral Decision Making 2000, I3:|45-I49.

49. Richards JB, Zhang L, Mitchell SH, de Wit H: Delay or probability discounting in a model of impulsive behavior: effect of alcohol. J Exp Anal Behav 1999, 71:121-143.

50. Kacelnik A: Normative and descriptive models of decision making: time discounting and risk sensitivity. Ciba Found Symp 1997, 208:51-67; discussion 67-70.

5I. Mackintosh NJ: The Psychology of Animal Learning. London, Academic Press; 1974.

52. Hall J, Parkinson JA, Connor TM, Dickinson A, Everitt BJ: Involvement of the central nucleus of the amygdala and nucleus accumbens core in mediating Pavlovian influences on instrumental behaviour. European Journal of Neuroscience 200I, 13:1984-1992.

53. de Borchgrave R, Rawlins JN, Dickinson A, Balleine BW: Effects of cytotoxic nucleus accumbens lesions on instrumental conditioning in rats. Exp Brain Res 2002, 144:50-68.

54. Parkinson JA, Robbins TW, Everitt B]: Selective excitotoxic lesions of the nucleus accumbens core and shell differentially affect aversive Pavlovian conditioning to discrete and contextual cues. Psychobiology 1999, 27:256-266.

55. Parkinson JA, Willoughby PJ, Robbins TW, Everitt BJ: Disconnection of the anterior cingulate cortex and nucleus accumbens core impairs Pavlovian approach behavior: Further evidence for limbic cortical-ventral striatopallidal systems. Behavioral Neuroscience 2000, I | 4:42-63.

56. Parkinson JA, Dalley JW, Cardinal RN, Bamford A, Fehnert B, Lachenal G, Rudarakanchana N, Halkerston KM, Robbins TW, Everitt B]: Nucleus accumbens dopamine depletion impairs both acquisition and performance of appetitive Pavlovian approach behaviour: implications for mesoaccumbens dopamine function. Behavioural Brain Research 2002, 137:|49-163.

57. Cardinal RN, Parkinson JA, Lachenal G, Halkerston KM, Rudarakanchana N, Hall J, Morrison CH, Howes SR, Robbins TW, Everitt B]: Effects of lesions of the nucleus accumbens core, anterior cingulate cortex, and central nucleus of the amygdala on autoshaping performance in rats. Behavioral Neuroscience 2002, I I 6:553-567

58. Cardinal RN, Parkinson JA, Hall J, Everitt BJ: Emotion and motivation: the role of the amygdala, ventral striatum, and prefrontal cortex. Neurosci Biobehav Rev 2002, 26:32I-352.

59. Cardinal RN, Everitt B]: Neural and psychological mechanisms underlying appetitive learning: links to drug addiction. Curr Opin Neurobiol 2004, 14:156-162.

60. Dickinson A, Balleine B: Motivational control of goal-directed action. Animal Learning \& Behavior 1994, 22: I- I8.

61. Dickinson A: Instrumental conditioning. In Animal Learning and Cognition Edited by: Mackintosh NJ. San Diego, Academic Press; 1994:45-79.

62. Kelley AE, Smith-Roe SL, Holahan MR: Response-reinforcement learning is dependent on $\mathrm{N}$-methyl-D-aspartate receptor activation in the nucleus accumbens core. Proc Natl Acad Sci U S A 1997, 94:12174-12179. 
63. Baldwin AE, Sadeghian K, Holahan MR, Kelley AE: Appetitive instrumental learning is impaired by inhibition of CAMP dependent protein kinase within the nucleus accumbens. Neurobiol Learn Mem 2002, 77:44-62.

64. Smith-Roe SL, Kelley AE: Coincident activation of NMDA and dopamine $D I$ receptors within the nucleus accumbens core is required for appetitive instrumental learning. J Neurosc 2000, 20:7737-7742.

65. Hernandez PJ, Sadeghian K, Kelley AE: Early consolidation of instrumental learning requires protein synthesis in the nucleus accumbens. Nat Neurosci 2002, 5: |327-133|.

66. Corbit LH, Muir JL, Balleine BW: The role of the nucleus accumbens in instrumental conditioning: evidence of a functional dissociation between accumbens core and shell. Journal of Neuroscience 200I, 21:325I-3260.

67. Mazur JE: Choice between small certain and large uncertain reinforcers. Animal Learning \& Behavior 1988, 16:199-205.

68. Kirby KN, Marakovic NN: Delay-discounting probabilistic rewards: Rates decrease as amounts increase. Psychonomic Bulletin \& Review 1996.

69. Giertler C, Bohn I, Hauber W: Involvement of NMDA and AMPA/KA receptors in the nucleus accumbens core in instrumental learning guided by reward-predictive cues. Eur J Neurosci 2005, 21:1689-1702.

70. Hauber W, Bohn I, Giertler C: NMDA, but not dopamine D(2), receptors in the rat nucleus accumbens are involved in guidance of instrumental behavior by stimuli predicting reward magnitude. Journal of Neuroscience 2000, 20:6282-6288.

7I. Giertler C, Bohn I, Hauber W: The rat nucleus accumbens is involved in guiding of instrumental responses by stimuli predicting reward magnitude. Eur J Neurosci 2003, I 8:1993-1996.

72. Martin-Iverson MT, Wilkie D, Fibiger HC: Effects of haloperidol and d-amphetamine on perceived quantity of food and tones. Psychopharmacology 1987, 93:374-38I.

73. Cardinal RN, Robbins TW, Everitt BJ: The effects of d-amphetamine, chlordiazepoxide, alpha-flupenthixol and behavioural manipulations on choice of signalled and unsignalled delayed reinforcement in rats. Psychopharmacology 2000, 152:362-375

74. Evenden JL, Ryan CN: The pharmacology of impulsive behaviour in rats: the effects of drugs on response choice with varying delays of reinforcement. Psychopharmacology 1996, 128: $161-170$.

75. Sozou PD: On hyperbolic discounting and uncertain hazard rates [ DOI: 10.1098/rspb.1998.0534 ]. Proceedings of the Royal Society of London Series B: Biological Sciences 1998, 265:20I 5-2020.

76. Green L, Myerson J: Exponential versus hyperbolic discounting of delayed outcomes: Risk and waiting time. American Zoologist 1996, 36:496-505.

77. Stevenson MK: A discounting model for decisions with delayed positive and negative outcomes. Journal of Experimental Psychology: General 1986, I I 5: I3I-I54.

78. Rachlin H, Castrogiovanni A, Cross D: Probability and delay in commitment. Journal of the Experimental Analysis of Behavior 1987, 48:347-353

79. Mazur JE: Theories of probabilistic reinforcement. Journal of the Experimental Analysis of Behavior 1989, 51:87-99.

80. Mazur JE: Conditioned reinforcement and choice with delayed and uncertain primary reinforcers. Journal of the Experimental Analysis of Behavior 1995, 63:139-150.

8I. Mazur JE: Choice, delay, probability, and conditioned reinforcement. Animal Learning \& Behavior 1997, 25:|3|-|47.

82. Mitchell SH: Discounting the value of commodities according to different types of cost. In Choice, Behavioral Economics and Addiction Edited by: Heather $\mathrm{N}$ and Vuchinich RE. Oxford, Elsevier; 2003:339-357.

83. Ostaszewski P, Green L, Myerson J: Effects of inflation on the subjective value of delayed and probabilistic rewards. Psychonomic Bulletin \& Review 1998, 5:324-333.

84. Green L, Myerson J, Ostaszewski P: Amount of reward has opposite effects on the discounting of delayed and probabilistic outcomes. J Exp Psychol Learn Mem Cogn 1999, 25:4 I8-427.

85. Myerson J, Green L, Hanson JS, Hold DD, Estle SJ: Discounting delayed and probabilistic rewards: Processes and traits. Journal of Economic Psychology 2003, 24:619-635.
86. Deakin J, Aitken M, Robbins T, Sahakian BJ: Risk taking during decision-making in normal volunteers changes with age. J Int Neuropsychol Soc 2004, 10:590-598.

87. Reynolds B, Richards JB, Horn K, Karraker K: Delay discounting and probability discounting as related to cigarette smoking status in adults. Behav Processes 2004, 65:35-42

88. Vuchinich RE, Calamas ML: Does the repeated gambles procedure measure impulsivity in social drinkers? Exp Clin Psychopharmacol 1997, 5:157-162.

89. Mitchell SH: Measures of impulsivity in cigarette smokers and non-smokers. Psychopharmacology 1999, 1 46:455-464.

90. Evenden JL: Varieties of impulsivity. Psychopharmacology 1999 , | 46:348-36|.

91. Christakou A, Robbins TW, Everitt BJ: Prefrontal cortical-ventral striatal interactions involved in affective modulation of attentional performance: implications for corticostriatal circuit function. I Neurosci 2004, 24:773-780.

92. Eagle DM, Robbins TW: Lesions of the medial prefrontal cortex or nucleus accumbens core do not impair inhibitory control in rats performing a stop-signal reaction time task. Behav Brain Res 2003, 146:131-144.

93. Taylor JR, Robbins TW: Enhanced behavioural control by conditioned reinforcers following microinjections of d-amphetamine into the nucleus accumbens. Psychopharmacology 1984 , 84:405-4I2.

94. Taylor JR, Robbins TW: 6-Hydroxydopamine lesions of the nucleus accumbens, but not of the caudate nucleus, attenuate enhanced responding with reward-related stimuli produced by intra-accumbens d-amphetamine. Psychopharmacology 1986, 90:390-397.

95. Cador M, Taylor JR, Robbins TW: Potentiation of the effects of reward-related stimuli by dopaminergic-dependent mechanisms in the nucleus accumbens. Psychopharmacology 1991, 104:377-385

96. Salamone JD, Correa M: Motivational views of reinforcement: implications for understanding the behavioral functions of nucleus accumbens dopamine. Behav Brain Res 2002, 137:3-25.

97. Salamone JD, Correa M, Mingote SM, Weber SM: Nucleus accumbens dopamine and the regulation of effort in foodseeking behavior: implications for studies of natural motivation, psychiatry, and drug abuse. J Pharmacol Exp Ther 2003, 305: $1-8$.

98. Ikemoto S, Panksepp J: The role of nucleus accumbens dopamine in motivated behavior: a unifying interpretation with special reference to reward-seeking. 0/65-0/73 1999, $3 I: 6-4 \mid$

99. Salamone JD, Correa M, Mingote SM, Weber SM: Beyond the reward hypothesis: alternative functions of nucleus accumbens dopamine. Curr Opin Pharmacol 2005, 5:34-4I.

100. Mingote S, Weber SM, Ishiwari K, Correa M, Salamone JD: Ratio and time requirements on operant schedules: effort-related effects of nucleus accumbens dopamine depletions. Eur J Neurosci 2005, 2 1: 1749-1757.

10I. Ostaszewski P, Karzel K: Discounting of delayed and probabilistic losses of different amounts. European Psychologist 2002, 7:295-30I.

102. Brog JS, Salyapongse A, Deutch AY, Zahm DS: The patterns of afferent innervation of the core and shell in the "accumbens" part of the rat ventral striatum: immunohistochemical detection of retrogradely transported fluoro-gold. Journal of Comparative Neurology 1993, 338:255-278.

103. Bechara A, Damasio AR, Damasio H, Anderson SW: Insensitivity to future consequences following damage to human prefrontal cortex. Cognition 1994, 50:7-15.

104. Bechara A, Tranel D, Damasio H, Damasio AR: Failure to respond autonomically to anticipated future outcomes following damage to prefrontal cortex. Cerebral Cortex 1996, 6:215-225.

105. Bechara A, Damasio H, Tranel D, Damasio AR: Deciding advantageously before knowing the advantageous strategy. Science 1997, 275:1293-1295.

106. Manes F, Sahakian B, Clark L, Rogers R, Antoun N, Aitken M, Robbins $\mathrm{T}$ : Decision-making processes following damage to the prefrontal cortex. Brain 2002, I 25:624-639.

107. Clark L, Manes F, Antoun N, Sahakian BJ, Robbins TW: The contributions of lesion laterality and lesion volume to decision- 
making impairment following frontal lobe damage. Neuropsychologia 2003, 4I:|474-|483.

108. Fellows LK, Farah MJ: Different underlying impairments in decision-making following ventromedial and dorsolateral fronta lobe damage in humans. Cereb Cortex 2005, 15:58-63.

109. Rogers RD, Owen AM, Middleton HC, Williams EJ, Pickard JD, Sahakian BJ, Robbins TW: Choosing between small, likely rewards and large, unlikely rewards activates inferior and orbital prefrontal cortex. Journal of Neuroscience 1999, 19:9029-9038.

I 10. Rogers RD, Ramnani N, Mackay C, Wilson JL, Jezzard P, Carter CS, Smith SM: Distinct portions of anterior cingulate cortex and medial prefrontal cortex are activated by reward processing in separable phases of decision-making cognition. Biol Psychiatry 2004, 55:594-602.

III. Rogers RD, Everitt BJ, Baldacchino A, Blackshaw AJ, Swainson R, Wynne K, Baker NB, Hunter J, Carthy T, Booker E, London M, Deakin JF, Sahakian BJ, Robbins TW: Dissociable deficits in the decision-making cognition of chronic amphetamine abusers, opiate abusers, patients with focal damage to prefrontal cortex, and tryptophan-depleted normal volunteers: evidence for monoaminergic mechanisms. Neuropsychopharmacology 1999, 20:322-339.

1 12. Mobini S, Body S, Ho MY, Bradshaw CM, Szabadi E, Deakin JF, Anderson IM: Effects of lesions of the orbitofrontal cortex on sensitivity to delayed and probabilistic reinforcement Psychopharmacology 2002, 160:290-298.

I 13. Kheramin S, Body S, Herrera FM, Bradshaw CM, Szabadi E, Deakin JF, Anderson IM: The effect of orbital prefrontal cortex lesions on performance on a progressive ratio schedule: implications for models of inter-temporal choice. Behav Brain Res 2005, 156: $145-152$.

114. Kheramin S, Body S, Ho MY, Velazquez-Martinez DN, Bradshaw CM Szabadi E, Deakin JF, Anderson IM: Effects of orbital prefrontal cortex dopamine depletion on inter-temporal choice: a quantitative analysis. Psychopharmacology (Berl) 2004, I75:206-2|4.

115. Kheramin S, Body S, Ho M, Velazquez-Martinez DN, Bradshaw CM, Szabadi E, Deakin JF, Anderson IM: Role of the orbital prefrontal cortex in choice between delayed and uncertain reinforcers: a quantitative analysis. Behav Processes 2003, 64:239-250.

116. Halliday G, Harding A, Paxinos G: Serotonin and tachykinin systems. In The Rat Nervous System Edited by: Paxinos G. London, Academic Press; 1995:929-974.

I 17. Mehlman PT, Higley JD, Faucher I, Lilly AA, Taub DM, Vickers J, Suomi S), Linnoila M: Low CSF 5-HIAA concentrations and severe aggression and impaired impulse control in nonhuman primates. American Journal of Psychiatry 1994, I 5 I: | 1485- |49|

1 18. Åsberg M, Träskman L, Thorén P: 5-HIAA in the cerebrospinal fluid: a biochemical suicide predictor. Archives of General Psychiatry 1976, 33: I 193-II97.

I19. Linnoila M, Virkkunen M, Scheinin M, Nuutila A, Rimon R, Goodwin FK: Low cerebrospinal fluid 5-hydroxyindoleacetic acid concentration differentiates impulsive from nonimpulsive violent behavior. Life Sciences 1983, 33:2609-2614.

120. Brown GL, Linnoila M: CSF serotonin metabolite (5HIAA) studies in depression, impulsivity and violence. Journal of Clinical Psychiatry 1990, 5 I (supplement 4):3 I-4I.

121. Linnoila M, Virkkunen M, George T, Higley D: Impulse control disorders. International Clinical Psychopharmacology 1993, 8 (Supplement I):53-56.

122. Mann J]: Neurobiology of suicidal behaviour. Nat Rev Neurosci 2003, 4:819-828

123. Biggio G, Fadda F, Fanni P, Tagliamonte A, Gessa G: Rapid depletion of serum tryptophan, brain tryptophan, serotonin and 5 hydroxyindoleacetic acid by a trytophan-free diet. Life Sciences 1974, 14:1321-1329.

124. Clemens JA, Bennett DR, Fuller RW: The effect of a tryptophanfree diet on prolactin and corticosterone release by serotonergic stimuli. Horm Metab Res 1980, I 2:35-38.

125. Delgado PL, Charney DS, Price LH, Landis H, Heninger GR: Neuroendocrine and behavioral effects of dietary tryptophan restriction in healthy subjects. Life Sci 1989, 45:2323-2332.

126. Anderson IM, Richell RA, Bradshaw CM: The effect of acute tryptophan depletion on probabilistic choice. J Psychopharmacol 2003, I 7:3-7.
127. Rogers RD, Tunbridge EM, Bhagwagar Z, Drevets WC, Sahakian B], Carter CS: Tryptophan depletion alters the decision-making of healthy volunteers through altered processing of reward cues. Neuropsychopharmacology 2003, 28: 153-162.

128. Mobini S, Chiang TJ, Ho MY, Bradshaw CM, Szabadi E: Effects of central 5-hydroxytryptamine depletion on sensitivity to delayed and probabilistic reinforcement. Psychopharmacology (Berl) 2000, 152:390-397.

129. Wade TR, de Wit H, Richards JB: Effects of dopaminergic drugs on delayed reward as a measure of impulsive behavior in rats. Psychopharmacology 2000, I50:90-101.

130. Winstanley CA, Theobald DE, Dalley JW, Robbins TW: Interactions between serotonin and dopamine in the control of impulsive choice in rats: therapeutic implications for impulse control disorders. Neuropsychopharmacology 2005, 30:669-682.

131. Rogers RD, Lancaster M, Wakeley J, Bhagwagar Z: Effects of betaadrenoceptor blockade on components of human decisionmaking. Psychopharmacology (Berl) 2004, I72:157-164.

132. O'Carroll RE, Papps BP: Decision making in humans: the effect of manipulating the central noradrenergic system. J Neurol Neurosurg Psychiatry 2003, 74:376-378

133. Aston-Jones G, Shipley MT, Grzanna R: The locus coeruleus, A5 and A7 noradrenergic cell groups. In The Rat Nervous System Edited by: Paxinos G. London, Academic Press; 1995:183-213.

134. Stroustrup B: The C++ Programming Language. Reading, Massachusetts, Addison-Wesley; 1986.

135. Cardinal RN, Aitken MRF: Whisker (version 2) [ www.whiskercontrol.com ]. Cambridge, UK, Cambridge University Technical Services Ltd; 2001.

136. Paxinos G, Watson C: The Rat Brain in Stereotaxic Coordinates. Fourth edition. London, Academic Press; 1998.

137. Howell DC: Statistical Methods for Psychology. Fourth edition. Belmont, California, Wadsworth; 1997

138. Levene $\mathrm{H}$ : Robust tests for the equality of variance. In Contributions to probability and statistics Edited by: Oklin I. Palo Alto, California, Stanford University Press; 1960.

139. Keppel G: Design and analysis: a researcher's handbook. Second edition. London, Englewood Cliffs: Prentice-Hall; 1982.

140. Mauchly JW: Significance test for sphericity of a normal n-variate distribution. Annals of Mathematical Statistics 1940, I I :204-209.

14I. Huynh H, Feldt LS: Conditions under which mean square ratios in repeated measures designs have exact F-distributions. lournal of the American Statistical Association 1970, 65: 1582-I589.

142. Sidák Z: Rectangular confidence regions for the means of multivariate normal distributions. Journal of the American Statistical Association 1967, 81:826-831.

Publish with BioMed Central and every scientist can read your work free of charge

"BioMed Central will be the most significant development for disseminating the results of biomedical research in our lifetime. "

Sir Paul Nurse, Cancer Research UK

Your research papers will be:

- available free of charge to the entire biomedical community

- peer reviewed and published immediately upon acceptance

- cited in PubMed and archived on PubMed Central

- yours - you keep the copyright
BioMedcentral 